\title{
I+D EN LA ESPAÑA DE LOS NOVENTA (GASTOS, INGRESOS Y PERSONAL)
}

\section{Pedro González Blasco}

Universidad Autónoma de Madrid

\section{RESUMEN}

Utilizando datos secundarios de diferentes fuentes sobre gastos, ingresos y personal español implicado en la $\mathrm{I}+\mathrm{D}$, se han actualizado y ampliado las series utilizadas en años anteriores desde 1974 y 1980 hasta 1992. Basándonos en esas tablas, se revisan las principales variaciones en el personal investigador, según diferentes tipos de investigadores, distintos campos y sectores de ejecución, en la Administración Pública, así como en las empresas privadas, considerando también el género del personal investigador. Se estudian los gastos realizados en $\mathrm{I}+\mathrm{D}$, en unas perspectivas general y relativa, comparando con otros países europeos y según fuentes de la financiación, origen y destino de los fondos en los sectores públicos y privados, distintos campos y tipos de investigación. Al final se resumen en nueve puntos los principales hallazgos obtenidos.

\section{INTRODUCCIÓN*}

Ciencia es algo que la gran mayoría desconoce, lo que no impide que se la respete. Todos disfrutamos de sus aplicaciones y algunos temen por las consecuencias que a veces puede acarrear. Un grupo de personas la conocen bien, la desarrollan y viven en ella; son los que conocemos como investigadores cientí-

* Agradezco a la Fundación BBV — Banco Bilbao Vizcaya - su apoyo económico, y a David López Orbiso su ayuda para reunir y tratar los datos de este trabajo.

\section{Reis}


ficos, para quienes su vida profesional se centra en la ciencia. Ese grupo ha sido estudiado en diversos contextos y desde diferentes perspectivas: los investigadores o científicos como "miembros de grupos concretos", como "profesionales», como «individuos creativos» y como «miembros de disciplinas específicas» ${ }^{1}$.

Desde esas perspectivas se analizaron su número, reclutamiento, productividad, organización, preparación, interrelaciones con otros grupos sociales, sus características propias y otra serie de aspectos. Éste ha sido uno de los campos de estudio de la denominada Sociología de la Ciencia ${ }^{2}$. La ciencia se entiende aquí, prioritariamente, como ciencia «natural», o sea, aquella que hace referencia a la materia y energía, y no tanto a la denominada ciencia «social». Así es como generalmente se entiende ciencia hoy cuando trata de ella el común de la gente. Desde esa distinción y refiriéndonos a la primera, se puede definir como «modo de conocimiento que aspira a formular mediante lenguajes rigurosos y apropiados —en lo posible con el auxilio del lenguaje matemáticoleyes por medio de las cuales se rigen los fenómenos» ${ }^{3}$ naturales. Para Fisher ${ }^{4}$, ciencia es «el cuerpo de conocimiento obtenido por métodos basados en la observación», o, como prefiere definirla Dampier ${ }^{5}$, «el conocimiento ordenado de los fenómenos naturales y el estudio racional de las relaciones entre los conceptos en que estos fenómenos son expresados». Los científicos son las personas que desarrollan la ciencia, en cualquiera de sus campos. Según Merton ${ }^{6}$, ese grupo de personas se mueve, en sus tareas profesionales, en un espacio ético-normativo, en un ethos peculiar regido por los principios de universalismo, comunalismo, desinterés o recompensa intrínseca por los descubrimientos de nuevos conocimientos y el reconocimiento de sus colegas, y, finalmente, el escepticismo organizado. Esta identificación mertoniana del universo éticonormativo en que se movería la comunidad científica ha sido ampliamente criticada por algunos autores, mientras que otros, aceptando básicamente las coordenadas señaladas por Merton, amplían éstas con otra serie de características.

Conocemos algunos aspectos de los investigadores científicos españoles de hace unos años. Entonces eran unos veinticinco mil, la mayoría trabajando en entidades públicas, en Madrid y parcialmente en Barcelona, procedentes de áreas más bien rurales o poblaciones de tamaño intermedio y mayoritariamente hombres. Su motivación para dedicarse a la investigación era «vocacional», les gustaba hacerlo, aunque no eran muy optimistas sobre su trabajo, en buena

1 N. W. STORER, The Social System of Science, Holt, Reinenhart and Wiston, N.Y., 1966.

${ }^{2}$ Ver para el caso de España: P. GONZÁlez Blasco, El Investigador científico en España, CIS, Madrid, 1980.

3 J. Ferrater Mora, Diccionario de Filosofía Abreviado, Edhasa, Barcelona, 1978.

${ }^{4}$ R. B. FISHER, Science, man and society, W. B. Saunders Company, Philadelphia, 1971.

5 W. C. Dampier, A History of Science, and its relation with Philosophy and Religion, Cambridge University Press, England, 1961.

${ }^{6}$ R. K. Merton, Sociología de la Ciencia, 2 vols., Alianza, Madrid, 1971. 
parte considerado obsoleto, no en las fronteras de lo que se hacía en otros lugares, aunque esperaban que España hiciera una contribución importante en los próximos años. Casi la tercera parte del personal investigador no había realizado su tesis doctoral, que no era requerida si se trabajaba en centros privados. La tesis se realizó por bastantes de ellos para asegurar el puesto de trabajo $y$, aunque importante, no motivó profundamente su vocación investigadora, por la forma en que se desarrolló. La "pura» motivación mertoniana de "hacer avanzar la ciencia» la participaban pocos. El proceso de motivación, en muchos, fue decreciendo en su intensidad, de más a menos, con el transcurso del tiempo, y en ese proceso influyó el escaso apoyo que "los mayores» dieron a los más jóvenes investigadores. Casi no existían las «escuelas» donde algunos se consideraban «maestros» y otros "discípulos» de alguien, aunque no dejaba de haber "colegios invisibles», en términos de B. Clark, que se apoyaban en sus trabajos.

Como grupo no encontraron una motivación para su vocación investigadora en los antecedentes culturales o en la tradición científica familiar. Las familias de este grupo de personas, en general, no tenían vinculaciones intelectuales con contextos culturales de importancia, aunque en este panorama los investigadores que trabajaban en empresas privadas fueron algo más influenciados por su tradición científico-familiar. Los científicos universitarios fueron más influenciados por sus familias en su aspecto docente que en su faceta investigadora. Existía un alto grado de inestabilidad profesional, al menos potencial, en la comunidad científica española. Una mayoría tuvo serias dudas en seguir en su labor investigadora en los comienzos de su carrera, de la que no estaban satisfechos, y habían pensado seriamente, alguna vez, en dejarla por la docencia, los negocios o trabajar en otro país. Sin embargo, las reducidas oportunidades reales de trabajo que había en la práctica fueron un factor importante para seguir en la investigación en España. La ley de Lotka también se cumplía aquí, pocos publicaban mucho y muchos publicaban poco ${ }^{7}$. Éste era el panorama hace quince años.

Veamos algunos hechos que se dan hoy.

\section{PERSONAL INVESTIGADOR}

Los datos más actualizados, contrastados, con que podemos contar son de 1992. Según estas estadísticas, en España el grupo de personas dedicadas a la $\mathrm{I}+\mathrm{D}$ son unas setenta y dos mil, más concretamente 72.822. La cantidad de personal ha ido creciendo paulatinamente desde 1970, pero el aumento ha sido mayor en los últimos diez años, de 1980 a 1992, en que se pasó de treinta mil (30.948) a los actuales (72.822) (gráfico 2.1).

Ver P. González Blasco, El Investigador cientifico en España, CIS, Madrid, 1980. 
En conjunto, el personal se ha multiplicado por 5 desde 1975 (gráfico 2.2).

Este crecimiento se ha producido en todo tipo de personal: en EJC, los científicos e ingenieros casi se han multiplicado por ocho (gráficos 2.3-2.5), siendo el diez el factor multiplicador con los técnicos, no así con el personal auxiliar general, que aumentó más moderadamente (gráfico 2.4). Comparativamente con otros países de nuestro entorno, seguimos sin embargo manteniendo las mismas posiciones relativas que hace varios lustros: Alemania, Reino Unido, Francia e Italia nos superan ampliamente, mientras que España se sitúa por delante de Grecia y Portugal (gráfico 2.6).

Considerando la calificación del personal, quizás lo más importante es que en estos veinte últimos años se ha producido una redistribución del mismo al crecer más los técnicos de grado medio, científicos e ingenieros, y menos el personal auxiliar (gráfico 2.4). El número de técnicos al multiplicarse por diez se ha situado en el 16\% del total del personal, cuando en 1970 representaban el $9 \%$.

Los científicos e ingenieros, que eran un 36\% del total en 1970 , son ahora el 57\% (gráfico 2.4).

Así ha crecido el peso relativo de los investigadores más cualificados, reduciéndose el del personal auxiliar.

El cambio en la estructura es casi tan importante como el meramente numérico.

Las causas del crecimiento del personal investigador pueden estar en el impulso dado a este sector por la llamada Ley de la Ciencia y los Programas Nacionales de Investigación que han seguido a la misma. En segundo lugar, al aumento del profesorado universitario, parte de cuyo tiempo se contabiliza como dedicado a la $\mathrm{I}+\mathrm{D}$, aunque esto hace que considerando el Equivalente a Jornada Completa (EJC) el número de personal investigador se reduzca bastante (de setenta y dos mil) en la práctica, pues no siempre se dedica a $\mathrm{I}+\mathrm{D}$ el tiempo "teóricamente» asignado.

En tercer lugar, ha crecido el número de becarios no sólo predoctorales sino también postdoctorales, y, finalmente, en el crecimiento amplio habido hay que considerar el que «naturalmente» se produce con el normal desarrollo de las instituciones.

En cualquier caso, el impulso neto dado al número de investigadores científicos en España ha sido notable en las últimas décadas.

Esto, por otro lado, también plantea algunos problemas como, por ejemplo, lograr la mejor integración de los «antiguos» y los «nuevos» investigadores o el acoplamiento a la organización regular de la I+D española de los becarios, sobre todo de los postdoctorales, que en conjunto suman hoy unos tres mil seiscientos noventa y dos, a los que habrá que añadir los cerca de catorce mil becarios predoctorales que irán concluyendo sus tesis en los próximos años.

Por sectores de ejecución, más de la cuarta parte $(29,3 \%)$ se encuentran en la Enseñanza Superior (gráfico 2.7), sector que ha experimentado un amplio 
crecimiento, ya que en 1974 , casi veinte años antes, sólo representaba el $11,4 \%$. Lo que de nuevo pone de manifiesto que el espectacular crecimiento del personal investigador se debe en buena parte a la creación de nuevas universidades y a la expansión de las ya existentes. Este personal sólo parcialmente se dedica a la investigación, pues la docencia ocupa buena parte de su tiempo.

Hay, sin embargo, que señalar que la adjudicación a programas a equipos universitarios ha permitido a éstos el contratar personal para ejecutar Programas de Investigación y, además, quizás más importante, formar equipos de investigación interdisciplinares e interdepartamentales, favoreciendo la colaboración entre universidades y departamentos universitarios, que a su vez han experimentado una importante reestructuración interna.

El peso relativo del personal que trabaja en el sector denominado "actividades de I+D integradas», es decir, del personal casi exclusivamente dedicado a investigación básica, aplicada y desarrollo tecnológico, ha descendido ligeramente, pues si en 1974 representaba el 48\% del total, en la actualidad (1992) es del $44 \%$.

Pero se constata de nuevo desde esta perspectiva sectorial que el personal de «servicios generales» es el que menos creció, reduciendo muy significativamente su porcentaje en el total, ya que en 1974 eran el $41 \%$ y ahora sólo el $27 \%$ (gráfico 2.7). Estas variaciones señalan que, dentro de la política de expansión de personal dedicado a la $\mathrm{I}+\mathrm{D}$, el énfasis se ha puesto en el personal más cualificado y directamente responsable de la investigación, pero que este personal puede encontrarse un tanto escaso de apoyo en los servicios generales. Este punto puede ser más llamativo en los centros universitarios, cuyo crecimiento repercute bastante en el aumento de personal investigador, pero muy escasos de personal auxiliar.

La distribución de personal por campos de investigación muestra una constante anteriormente detectada (1970-1980), una concentración de efectivos en ingeniería y tecnología, lo que muestra la política seguida de hecho, coherente con las necesidades de la industria española, aunque el porcentaje hoy $(46 \%)$ ha descendido relativamente respecto al año 1976 (66\%).

El segundo campo al que se dedica el personal investigador es el de Ciencias Sociales, Humanidades y Ciencias Jurídicas, campo que ocupaba el último lugar hace veinte años. Posiblemente, en este incremento de las Ciencias Sociales, Humanidades y Jurídicas ha influido la mayor incorporación y el incremento de los profesores universitarios y la reestructuración de esos departamentos dentro del sistema español de I+D.

Dos campos, Ciencias Exactas y Naturales y Medicina, se sitúan en tercer lugar con un $14 \%$ del personal, subiendo muy moderadamente con relación a lo que había en 1976, aproximadamente un $10 \%$.

En último lugar continúa la investigación en agricultura y ganadería, que incluso ha reducido su peso relativo ( $9 \%$ versus $10,4 \%$ en 1976 ) en el conjunto del personal investigador (gráfico 2.8). 
Sigue siendo algo poco explicable en un país como España, donde la agricultura y ganadería tienen una importancia grande, especialmente en algunas zonas, y cuando la cualificación de los productos agrícolas y ganaderos es una necesidad que emana de las exigencias de la incorporación de España a la Comunidad Económica Europea (CEE), cuyas limitaciones en esos campos está afectando mucho al campo español. Si en algún momento ha sido más necesaria la investigación en lo referente a la agricultura y ganadería es ahora que somos parte de una CEE muy competitiva con nuestros productos.

Considerando el personal dedicado a $\mathrm{I}+\mathrm{D}$ en la Administración Pública y en las empresas, nos encontramos con pautas políticas diferentes en cuanto a las actividades a que se dedica ese personal.

En la Administración las actividades de «ingeniería y tecnología» ocupan a más de la cuarta parte de personal $(28 \%)$, pero porcentajes cercanos a ése se dedican también a la investigación «agrícola y ganadera» $(25,7 \%)$, a la medicina $(20,9 \%)$ y a las ciencias exactas y naturales $(19,6 \%)$.

Comparativamente con la distribución que se daba en 1973, aquí han bajado, porcentualmente, las actividades de ciencias y, sobre todo, de ingeniería-tecnología, creciendo el personal dedicado a todas las demás (gráfico 2.9).

Parece, pues, que, habiéndose incrementado el personal de todas las actividades, se han «equilibrado» las plantillas, aumentando porcentualmente más las de investigación médica, agricultura, ganadería y, en parte, ciencias sociales, humanidades y jurídicas. La fuerte orientación hacia la ingeniería-tecnología se ha moderado bastante.

La estructura de personal de los Centros de Investigación de la Administración Pública pone de manifiesto un cierto cambio en la dirección de la investigación. No ocurre lo mismo en el caso de las empresas, donde la orientación de la política de personal ha reforzado las actividades de «ingeniería y tecnología», netamente mayoritarias $(86 \%)$, que han aumentado incluso su peso relativo respecto al que tenían $(80,6 \%)$ hace veinte años (1973).

Todas las demás actividades de investigación realizadas en las empresas han visto disminuir porcentualmente su personal investigador, siendo muy bajo $(3,6 \%)$ el dedicado a ganadería-agricultura y casi simbólico $(0,3 \%)$ el personal que hace investigación en Ciencias Sociales, Jurídicas y Humanidades (ver gráfico 2.9).

Las pautas de dedicación de personal son, pues, bastante diferentes: mientras que en la Administración Pública se atiende a una diversidad de actividades investigadoras, en las empresas se concentra todo el esfuerzo en la ingeniería-tecnología, especialmente en la manufacturación de productos, sobre todo metálicos. Esto parece indicar una divergencia de intereses y, por tanto, de objetivos en la $\mathrm{I}+\mathrm{D}$, entre lo público (Administración) y lo privado (empresas).

También se ha producido un cambio relativo en la composición por sexos del personal dedicado a I+D. De más de cuatro hombres por cada mujer $(4,4)$ 
en 1976 se ha pasado a algo más (2,48 hombres por cada mujer) en estas actividades. Sigue prevaleciendo el número de hombres, pero la diferencia se ha acortado sensiblemente. Si distinguimos por niveles de formación, en el máximo nivel de investigadores la relación 6 a 1 de hombres a mujeres se redujo a 2,6 por cada mujer. Pero en el nivel que más se ha notado, y donde radica la mayoría del cambio, es en el nivel de técnicos-medios, en el que de 14 hombres por mujer en 1976 se ha pasado a algo más $(4,23)$ de cuatro a una.

En el caso del personal auxiliar, que ya era donde menor diferencia había, también se ha equilibrado algo la relación hombres/mujeres, situándose en 1992 en 1,76 a 1. Parece claro que no sólo la voluntad política, sino también el mayor nivel medio de educación formal alcanzado por las mujeres, ha tenido influencia en ese relativo cambio (gráfico 2.10).

Sin embargo, la mayor participación paulatina de las mujeres en tareas de $\mathrm{I}+\mathrm{D}$ muestra diferencias significativas según las distintas disciplinas científicas que se consideren. Así, en campos como Ingeniería y Tecnología, incluso en Ciencias Exactas, Naturales y Agrarias, los porcentajes de mujeres son más bajos, sobre todo, como investigadoras $y$, en menor medida, como técnicas (gráfico 2.10).

Por el contrario, la incorporación de la mujer es ya bastante más significativa en las Ciencias Médicas, donde son ya el 52\% del total en los Centros de la Administración, no tanto como investigadoras (38\%), sino como personal técnico $(72 \%)$, lo que en buena parte ocurre también en Ciencias Sociales y Humanidades. En cualquier caso y, sobre todo, considerando la ocupación en «equivalencia a dedicación plena», los porcentajes, en general, reflejan mayor proporción de hombres y distintos valores según los campos y disciplinas (gráfico 2.11).

En las empresas, la investigación y el desarrollo cuentan con mucho menos porcentaje de mujeres que en la Administración Pública, mientras que en la enseñanza superior se da un nivel que puede calificarse de intermedio (31\% de mujeres) (gráfico 2.12). Parece, pues, que la incorporación de la mujer a la $\mathrm{I}+\mathrm{D}$, sobre una base siempre existente, es un proceso lento pero ascendente en diferente ritmo según campos, disciplinas o tipos de ocupación. 


\section{GRÁFICO 2.1}

Personal total dedicado a $I+D\left(^{*}\right)$. España, 1970-1992

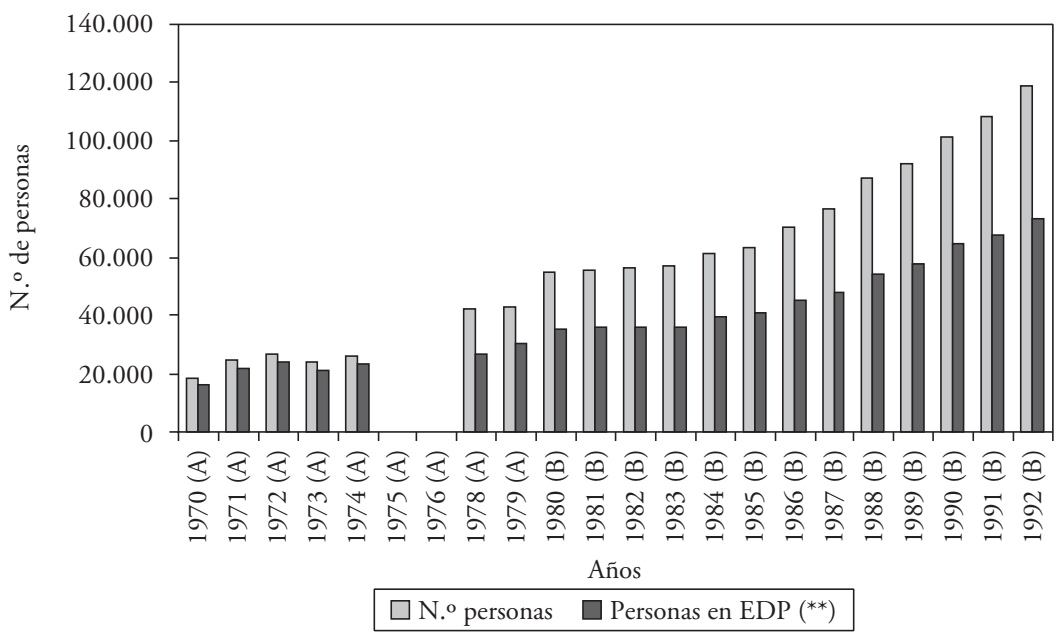

(*) No se incluye el Sector IPSFL.

$\left.{ }^{* *}\right) \quad \mathrm{EDP}=$ Equivalencia a Dedicación Plena.

Fuentes: (A) Estadística sobre las Actividades en I+D. Años 1978-81, INE, Madrid, 1985.

(B) Estadística sobre las Actividades en I+D. Año 1992, INE, Madrid, 1993.

\section{GRÁFICO 2.2}

Investigadores (cientificos e ingenieros) dedicados a $I+D(*)$. España, 1970-1992

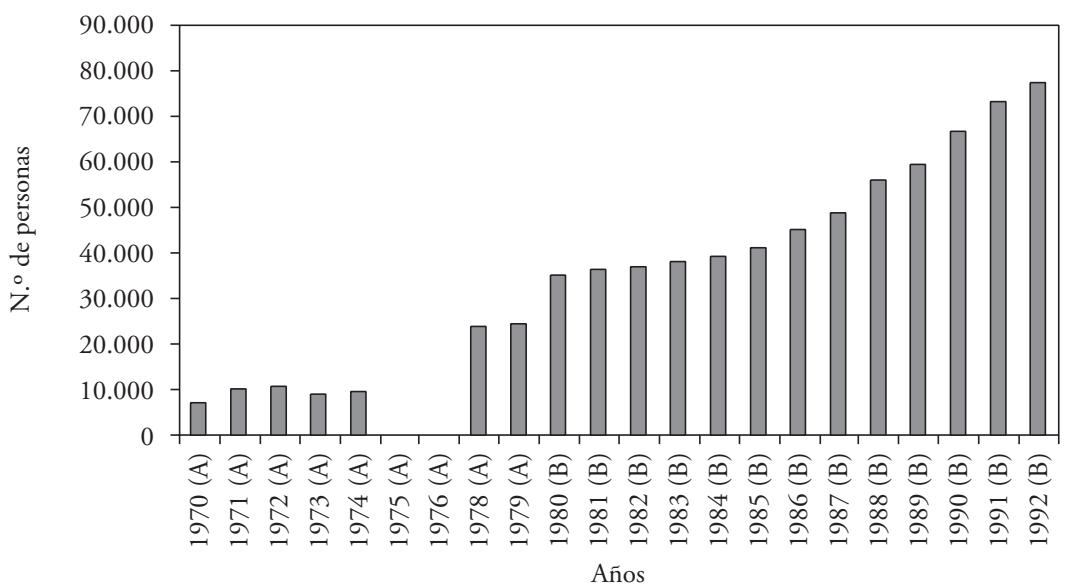

(*) No se incluye el Sector IPSFL.

Fuentes: (A) Estadística sobre las Actividades en I+D. Años 1978-81, INE, Madrid, 1985.

(B) Estadística sobre las Actividades en I+D. Año 1992, INE, Madrid, 1993. 


\section{GRÁFICO 2.3}

Porcentajes de personal empleado en $I+D\left(^{*}\right)$ según su nivel de formación en EJC (equivalente a jornada completa), 1970-1992

1970

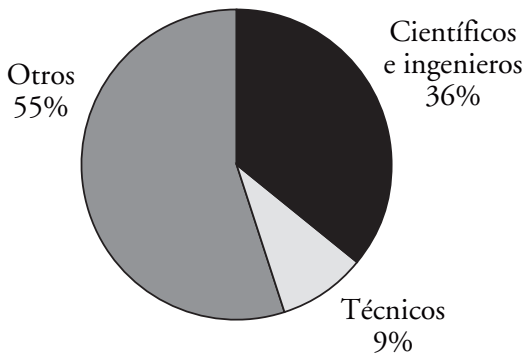

1992

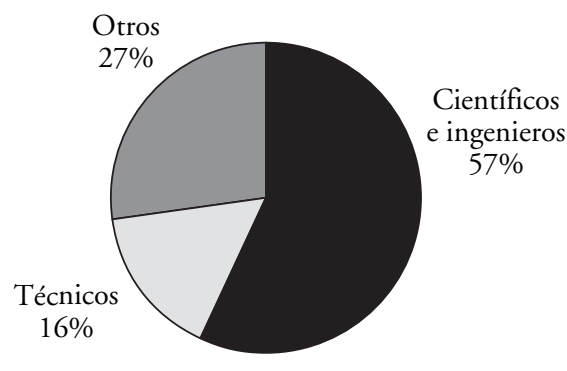

$\left(^{*}\right)$ Incluye técnicos del Sector Enseñanza Superior.

EJC: Equivalencia a Jornada Completa $\oplus$ EDP: Equivalencia a Dedicación Plena.

FUENTES: (1) INE, 1973.

(2) INE, 1975. Datos provisionales hasta su publicación por el INE.

(3) INE, 1976. Datos provisionales hasta su publicación por el INE.

(4) Estadistica sobre las Actividades en I+D. Años 1978-1987, INE, Madrid, 1985.

(5) Estadistica sobre las Actividades en I+D. Año 1992, INE, Madrid, 1993. 


\section{GRÁFICO 2.4}

Personal empleado en $I+D$ según su nivel de formación para diferentes años en equivalencia a jornada completa (EJC)

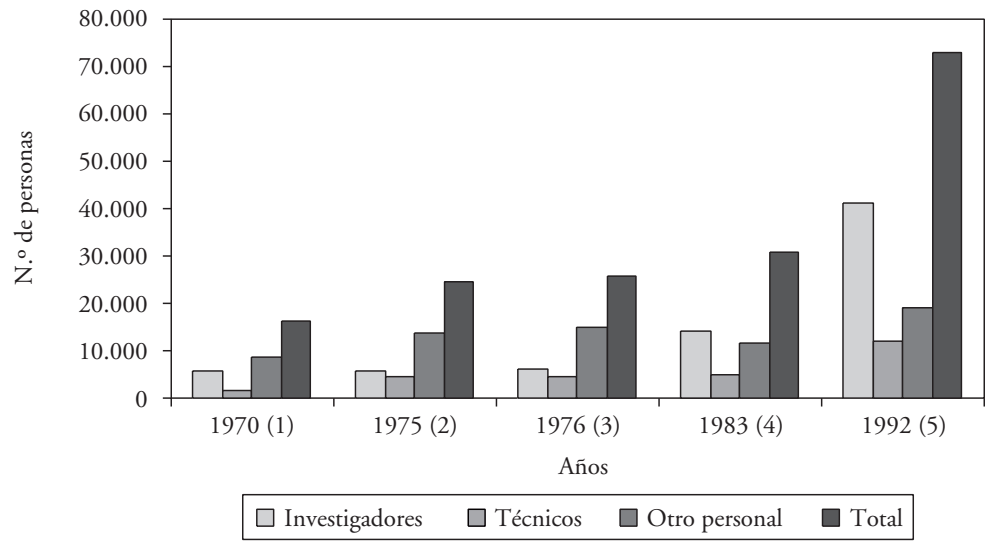

Fuentes: (1) INE, 1973.

(2) INE, 1982. Datos provisionales hasta su publicación por el INE (1975).

(3) INE, 1982. Datos provisionales hasta su publicación por el INE (1976).

(4) Estadistica sobre las Actividades en I+D. Años 1978-81, INE, Madrid, 1985.

(5) Estadistica sobre las Actividades en I+D. Año 1992, INE, Madrid, 1993.

\section{GRÁFICO 2.5}

Personal empleado a actividades de $I+D$.

Cientificos e ingenieros para diferentes años (España). Indices

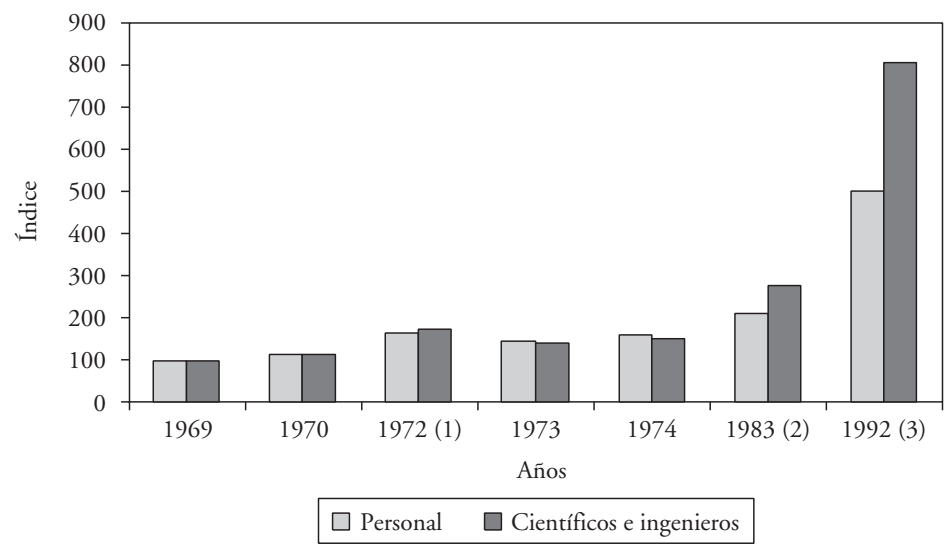

Nota: (2) y (3) son personal en equivalencia a dedicación plena.

Fuentes: (1) Anuario Estadístico 1981, UNESCO, p. V-75.

(2) Estadística sobre las Actividades en I+D. Años 1978-81, INE, Madrid, 1985.

(3) Estadistica sobre las Actividades en I+D. Año 1992, INE, Madrid, 1985. 


\section{GRÁFICO 2.6}

Personal científico y técnico en $I+D$

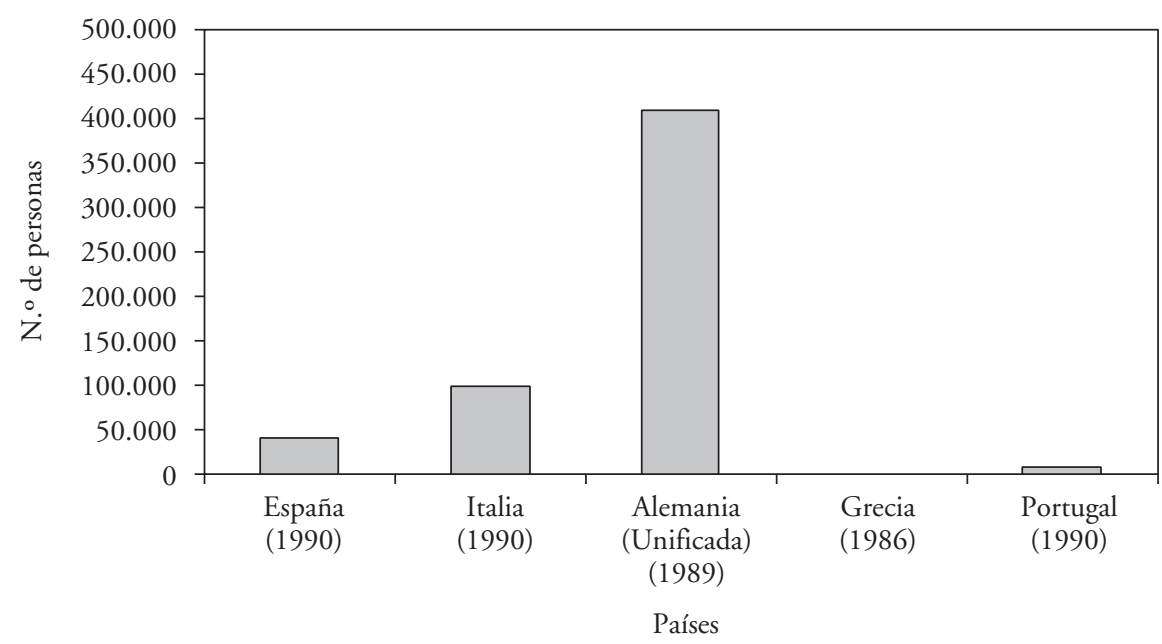

FUENTE: Anuario Estadistico 1994, UNESCO.

\section{GRÁFICO 2.7}

Personal de I+D por sector de ejecución. España, 1990

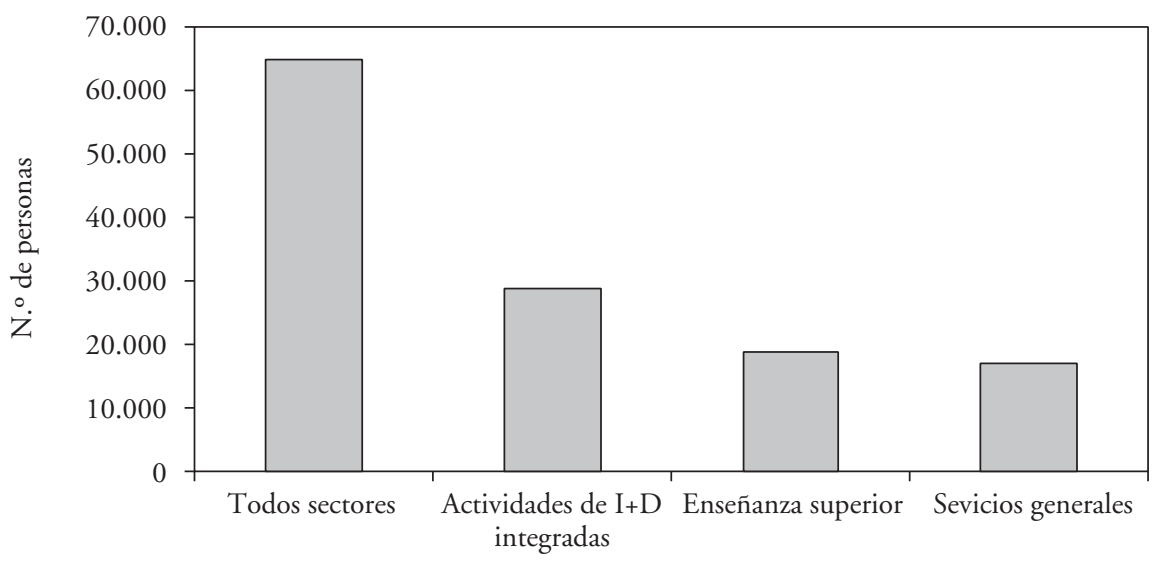

Sectores

FUENTE: Anuario Estadistico 1994, UNESCO. 


\section{GRÁFICO 2.8}

Personal dedicado a $I+D$ en EJC, por campos o disciplina científica. Año 1992

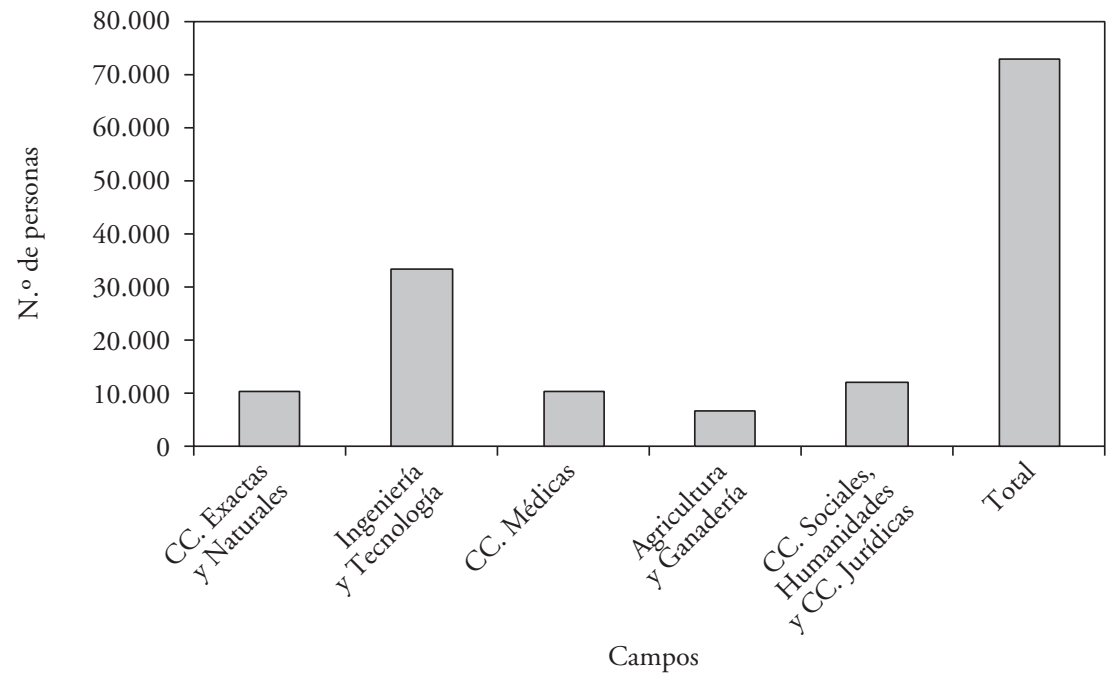

FuENTE: Estadistica sobre las Actividades en I+D. Año 1992, INE, Madrid, 1993.

\section{GRÁFICO 2.9}

Personal dedicado a actividades de I+D en EJC, por sectores. Año 1992

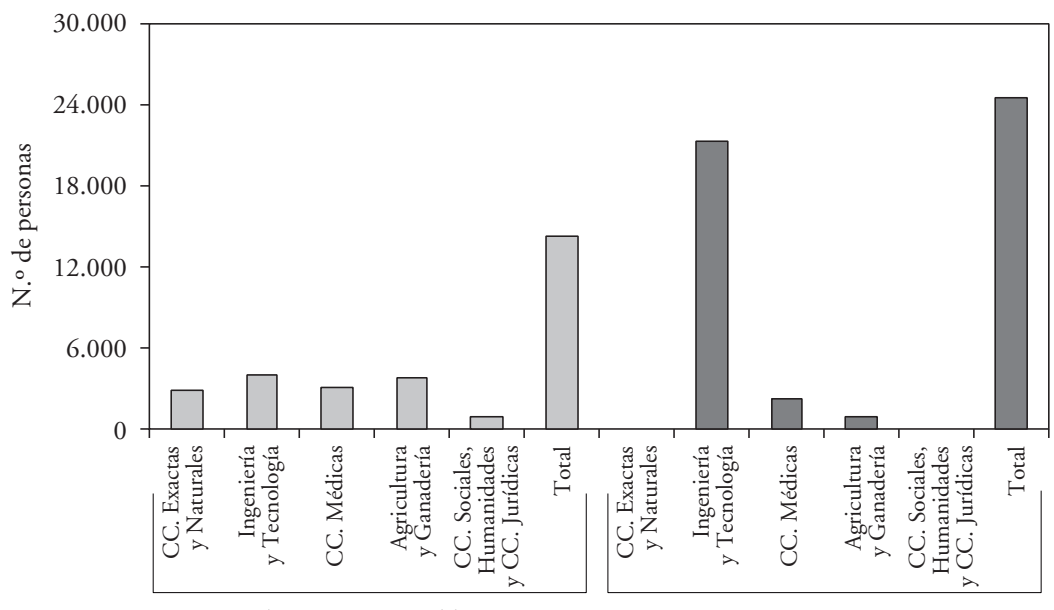

Administración Pública

Empresas

Sectores

Fuente: Estadistica sobre las Actividades en I+D. Año 1992, INE, Madrid, 1993. 


\section{GRÁFICO 2.10}

Personal empleado en $I+D$, clasificado según género y campo o disciplina cientificos (dedicación plena y parcial). España, 1992

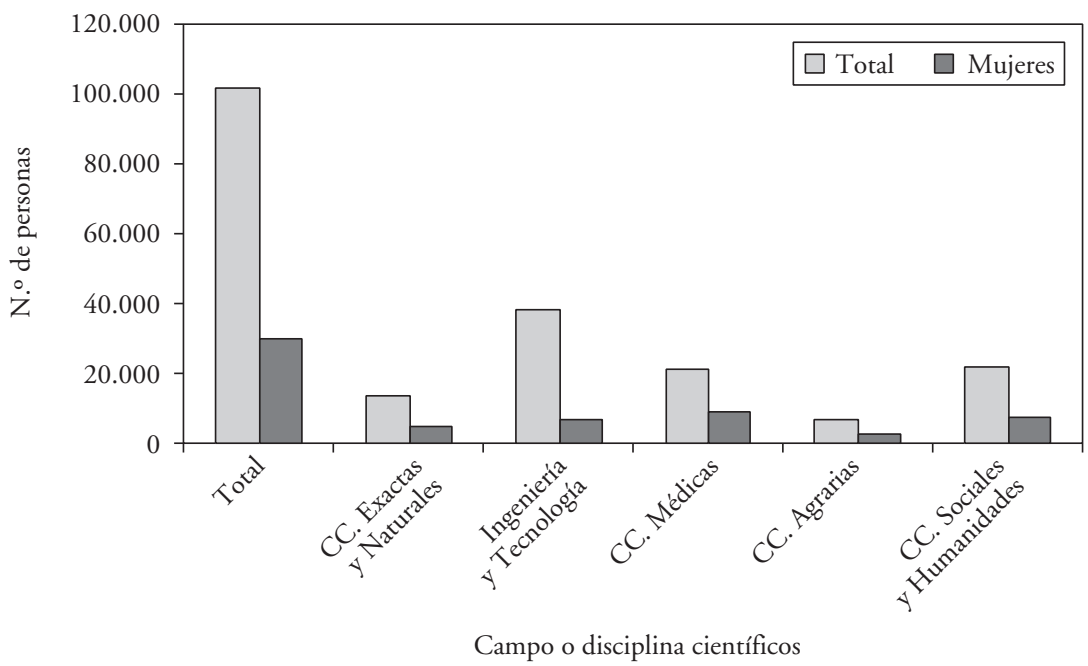

FUENTE: Estadistica sobre las Actividades en I+D. Año 1992, INE, Madrid, 1993.

\section{GRÁFICO 2.11}

Personal empleado en $I+D$, clasificado según género y campo o disciplina cientificos (dedicación plena). Sector: Administración Pública. Año 1992

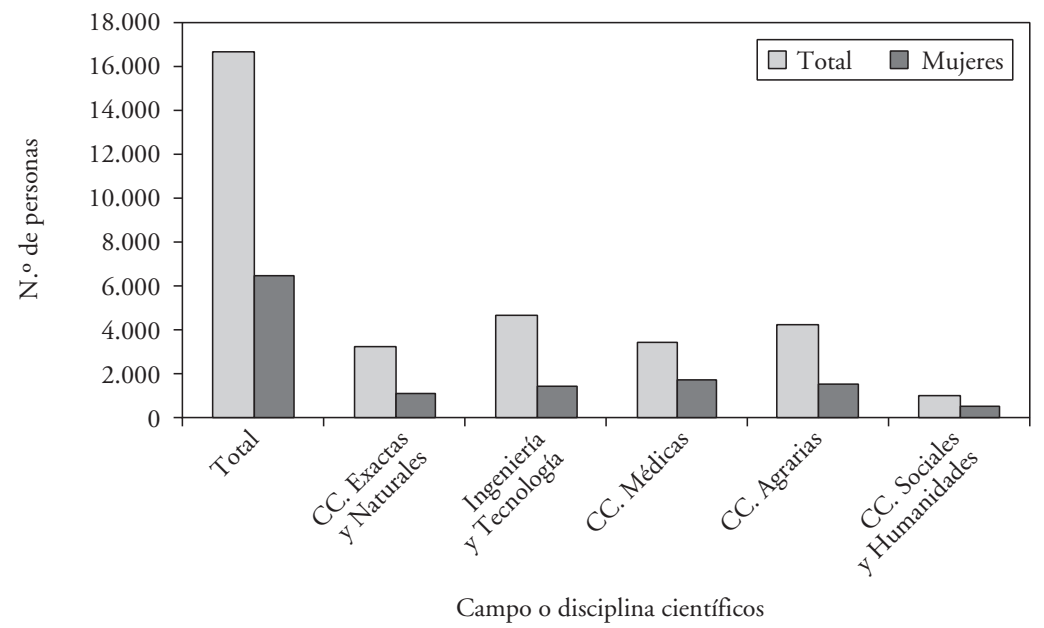

FuENTE: Estadística sobre las Actividades en I+D. Año 1992, INE, Madrid, 1993. 


\section{GRÁFICO 2.12}

Personal dedicado a actividades de $I+D$, según género y rama de actividad económica (dedicación plena). Sector: Empresas. Año 1992

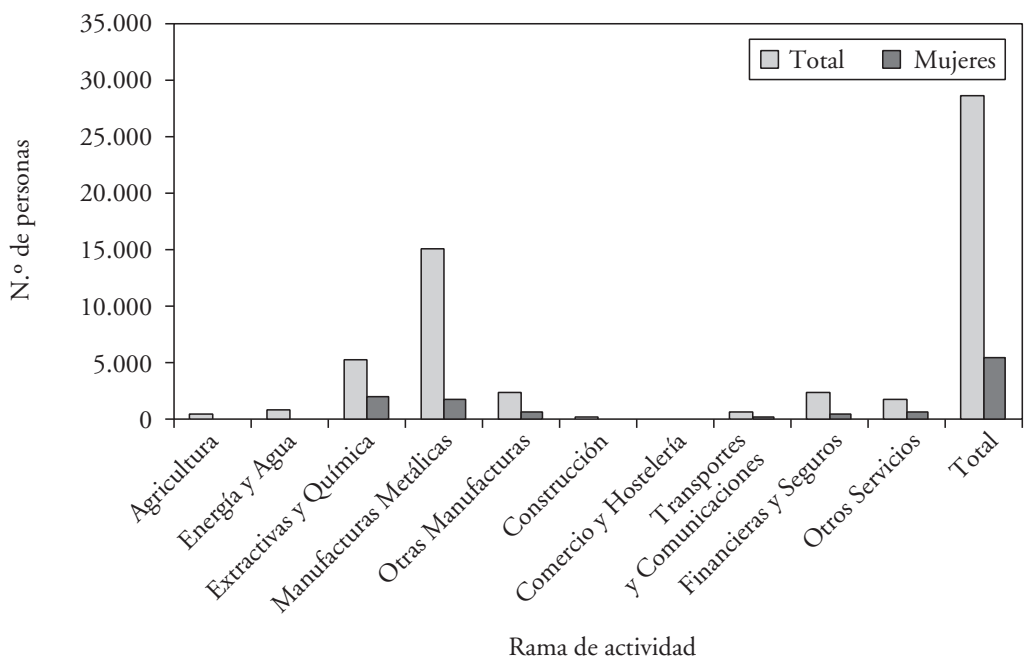

FueNTE: Estadistica sobre las Actividades en I+D. Año 1992, INE, Madrid, 1993.

\section{GRÁFICO 2.13}

Personal empleado en actividades de $I+D$, según género y campo o disciplina científicos (dedicación plena y parcial). Sector: Enseñanza Superior. Año 1992

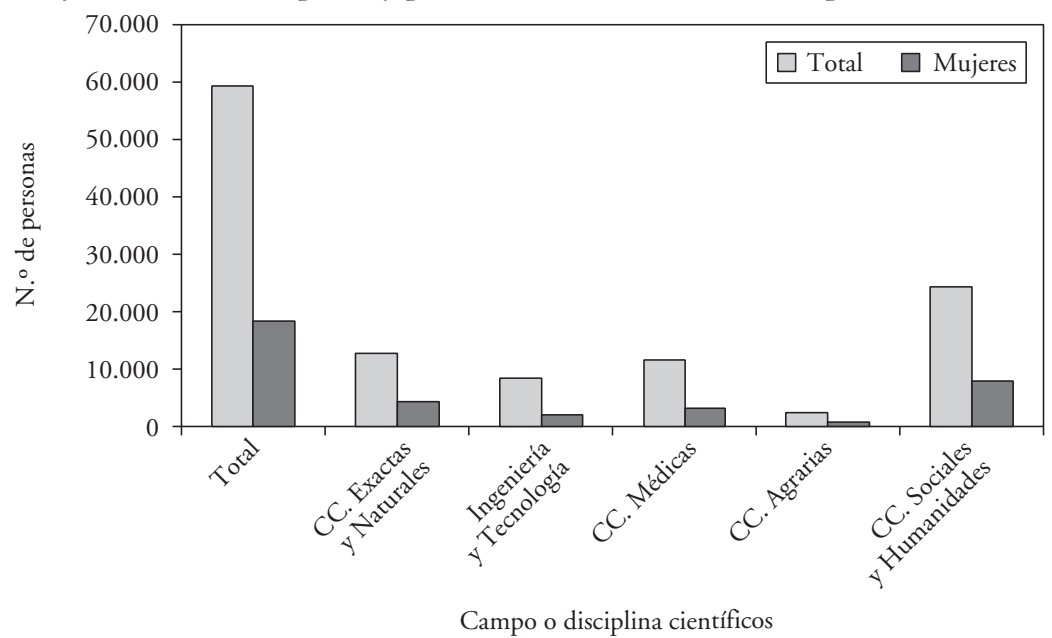

FuENTE: Estadistica sobre las Actividades en I+D. Año 1992, INE, Madrid, 1993. 


\section{GASTOS EN I+D}

El capital dedicado a la Investigación y Desarrollo (I+D) ha sido siempre escaso en España, según la opinión de los más directamente implicados. Sin embargo, desde hace varios lustros, las cantidades dedicadas han ido incrementándose año tras año. Si en 1970 el gasto total rozaba los seis mil millones de pesetas (5.593 millones de pesetas corrientes), cinco años después se había multiplicado casi por cuatro; pero ha sido en los últimos años, en gran parte como consecuencia de la promulgación de la Ley de la Ciencia y de los Programas Nacionales, cuando el incremento de gastos ha sido realmente significativo.

Así, en 1990, la cantidad destinada a $\mathrm{I}+\mathrm{D}$ se elevó a cuatrocientos veinticinco mil millones (463.084 en pesetas deflactadas), un índice de 760 sobre la base 100 de 1970. En el año 1994 se sobrepasa ya el medio billón (542.392 pesetas corrientes) en los gastos. Aun considerando la inflación acumulada en esos años, el aumento neto ha sido grande, significando una clara voluntad de apoyo a la investigación (ver gráfico 3.1).

Las cifras absolutas sólo reflejan, en parte, el esfuerzo hecho. Considerando los gastos en relación con el Producto Interior Bruto, se puede matizar mejor lo dedicado a $\mathrm{I}+\mathrm{D}$. Si durante bastantes años ${ }^{8}$ la relación de los gastos respecto al PIB se mantuvo en torno al 0,3-0,4\%, ya en 1990 se alcanzó el 0,85. En años posteriores, 1992-93, roza el 1\% si se incluyen las Instituciones Privadas sin ánimo de lucro (IPSFL) (gráfico 3.2).

El incremento, pues, ha sido claro, pero aún queda lejos de lo proyectado, que era sobrepasar el $1 \%$ para 1985 . La realidad es que se mejoró pero no en lo esperado, ni quizás en lo necesario. Las dificultades económicas generales al final de los años ochenta impidieron situarse en las cotas deseadas, suponiendo una ralentización a los proyectos en $\mathrm{I}+\mathrm{D}$. Lógicamente, el incremento en los gastos tiene relación con el ya señalado aumento del personal investigador. Aun con el incremento registrado, el porcentaje de gastos actual sobre el PIB nos sitúa bastante lejos de países desarrollados que dedican casi tres-cuatro veces más que España a su I+D. Frente a nuestro 0,85-1\%, Alemania dedica en 1993 el 2,76\% de su PIB, Francia el 2,42\%, el Reino Unido el 2,19\%, en nuestro entorno, y Estados Unidos el 2,73\%, bajo el 3,08\% que invirtió Japón (gráfico 3.3). Así, pues, otros países europeos ponen más interés en financiar su investigación, contando con sus recursos, lo que hace muy difícil nuestra "convergencia» en este campo con Europa en su conjunto. La mayoría de estos países no sólo invierten más dinero, sino que cuentan también con instituciones y organización capaces de rentabilizar mejor sus gastos. Así, a pesar del esfuerzo español en inversión, gastos y personal, se mantiene la diferencia con otros países y el "distanciamiento» sigue siendo importante, haciendo aún

${ }^{8}$ P. ej., ver P. González Blasco, Investigación y Desarrollo en España 1970-80, IV Informe FOESSA, Madrid. 
insuficiente ese esfuerzo. Como veremos más adelante, esto se refleja también en el déficit de la balanza de pagos española por transferencia tecnológica.

El aporte financiero-económico que sustenta los gastos en $\mathrm{I}+\mathrm{D}$ procede del Estado, a través de los fondos públicos aportados por sus distintas instituciones nacionales y autonómicas $(50,2 \%)$, y casi en la misma proporción por las empresas $(44,3 \%)$. Si consideramos que entre las empresas se incluyen tanto las privadas como las públicas — dependientes estas últimas de organismos estatales o autonómicos-, teniendo en cuenta además la aportación que suponen los denominados "fondos especiales», en buena parte también fondos públicos, podemos concluir que es el Estado el patrocinador principal de la investigación y el desarrollo tecnológico en España (gráfico 3.4). La aportación de entidades extranjeras se sitúa siempre en unos porcentajes pequeños $(5,5 \%$ en 1992), pero que han ido creciendo algo sobre todo en los últimos años (gráfico 3.4), situándose en unos veintinueve mil millones de pesetas constantes (gráfico 3.6). En esas cantidades se incluye lo que invirtieron en $\mathrm{I}+\mathrm{D}$ las empresas extranjeras, así como los fondos obtenidos de otros organismos extranjeros, principalmente europeos.

La evolución del origen de fondos entre 1974 y 1992 muestra que la relación fondos públicos a fondos privados (empresas y especiales) ha ido variando, pues de ser casi 40 a $60(57,4 \%)$, esa relación era ya en 1992 de 50 a 44 (ver gráfico 3.5), habiendo aumentado el peso relativo de los fondos públicos en el total. Todo ello tanto en pesetas corrientes como en pesetas constantes (ver gráfico 3.6).

También han aumentado, en un nivel inferior pero significativamente, las aportaciones extranjeras a la I+D en España ( $2 \%$ en 1974 a 5,5\% en 1992). Este incremento, aun con sus fluctuaciones, puede poner de manifiesto que, con el ingreso de España en la Unión Europea, empresas españolas, públicas y privadas, han entrado más en relación con empresas extranjeras, así como el que otros Centros de Investigación también han tenido mayor acceso y participación a programas europeos de $\mathrm{I}+\mathrm{D}$.

La distribución de los fondos en el sector público pone de manifiesto el peso relativo del mundo universitario, con el 29,1\% del gasto frente al $20 \%$ de otros organismos de la Administración Pública, como puede verse en el gráfico 3.7. Más adelante veremos algo más en detalle la $\mathrm{I}+\mathrm{D}$ en las universidades estatales.

La mayor parte de los gastos han ido a "gastos corrientes», el $80,1 \%$ en 1992, y de estos "corrientes» también un alto porcentaje se dedicó a personal, fundamentalmente retribuciones, el $72 \%$ en ese mismo año de 1992. La variación de los gastos corrientes sobre el total de gastos no ha variado mucho desde 1970 hasta la actualidad, aunque ese porcentaje ha subido algo en los últimos años (gráfico 3.8), quedando aproximadamente un $20 \%$ para «otros gastos de capital», inversiones, nuevos proyectos y otros capítulos diferentes de las retribuciones y el mantenimiento de lo existente, otros gastos corrientes (27\% del total de gastos corrientes) (gráficos 3.9 y 3.10). 
El gasto se orienta, mayoritariamente $(49,2 \%)$, hacia las empresas, hacia las actividades de $\mathrm{I}+\mathrm{D}$ «integradas», en terminología de la UNESCO; es decir, a organizaciones en que la investigación y el desarrollo se unen a otras tareas de producción de bienes y servicios. Ese porcentaje, con algunas variaciones, se mantiene desde hace años (gráfico 3.11). La investigación en los Centros de Enseñanza Superior, fundamentalmente Universidades estatales, consume el $30 \%$ del total del gasto en 1994 , porcentaje que ha subido casi cuatro veces desde 1974, coherentemente con el aumento relativo del personal universitario parcialmente ocupado en la investigación. El sector público o, como en los últimos años lo denomina la UNESCO, «servicios generales» absorbe aproximadamente $1 / 5$ de los gastos, lo que en su mayor parte va a los organismos de $\mathrm{I}+\mathrm{D}$ propios de las distintas Administraciones Públicas. En este último sector se ha producido un descenso continuo y significativo del porcentaje de gasto en relación al total, lo que puede deberse a un descenso neto del gasto, pero también a modificaciones en la contabilidad y, sobre todo, al efecto del aumento de gasto en los Centros de Enseñanza Superior y, por tanto, a una disminución relativa de los "gastos generales» o del sector público (gráficos 3.11 y 3.12). La evolución de la distribución del gasto entre los tres sectores considerados muestra también que en las últimas décadas se ha ido produciendo un cambio no sólo en lo cuantitativo, sino posiblemente también en la orientación del gasto. Estas modificaciones distributivas, sobre todo entre el sector público y la Enseñanza Superior, no sabemos bien si se han producido directamente o simplemente son consecuencias inducidas por otros cambios tales como el incremento del profesorado universitario o las adjudicaciones de los Programas Nacionales de Investigación. Algunos cambios quizás se deben más a la Ley de Reforma Universitaria que a la Ley de la Ciencia.

En cada sector de actividad, de ejecución y considerando las disciplinas científicas entre las que se distribuyen los gastos, vemos que éstos han afectado a dichas disciplinas en el mismo sentido en que el porcentaje afecta a cada sector. Así, en el sector de la enseñanza superior, cuyo porcentaje subió en los últimos años, todas las disciplinas han experimentado también incrementos relativos en sus gastos. Lo contrario sucede en general en otro sector: el de la Administración Pública; mientras que casi se mantiene invariable, por disciplinas, el sector de las empresas (gráficos 3.12 y 3.13).

Considerando los organismos dependientes, la Administración Pública, los gastos en $\mathrm{I}+\mathrm{D}$ se han reducido porcentualmente en todas las disciplinas científicas, excepto en medicina, donde han crecido de un $7,8 \%$ en 1976 a un $16,4 \%$ en 1992 , y ligeramente en investigación agrícola y ganadera $(18,6 \%$ a $20,7 \%)$. El mayor peso relativo de las ciencias médicas ha podido estar impulsado por la demanda y presión no sólo científica, sino social, ante enfermedades como el cáncer y el sida, u otras enfermedades socialmente llamativas. También pueden deberse simplemente a reajustes internos no suficientemente previstos, o a falta de control en esos gastos (gráfico 3.14). El aumento porcentual de los gastos en esas dos disciplinas coincide con un aumento muy mode- 
rado de los mismos en personal investigador, incluso con un ligero descenso en relación con el personal auxiliar, lo que sugiere una dedicación de mayores gastos a otras partidas. En general, parece que por la dedicación del gasto tanto en investigación y desarrollo agrícola y ganadero como, sobre todo, en ciencias médicas se ha producido una reorientación del gasto en los organismos de las Administraciones Públicas (gráfico 3.15). En este sector de las Administraciones Públicas el mayor porcentaje de gastos fueron gastos corrientes $(74 \%)$, restando aproximadamente $1 / 5(26 \%)$ para gastos de capital, básicamente equipos e instrumentos. La mayor parte de los gastos corrientes se destinaron a retribuciones (gráfico 3.16). Los fondos para sufragar los gastos los aportó fundamentalmente la Administración central (78\%), contribuyendo las Administraciones autonómicas en un $13 \%$, y en muy escasa medida las Corporaciones Locales $(1,8 \%)$, en tanto que las empresas aportaron en torno al $4 \%$ y del extranjero llegó un 2,7\%. Así, pues, la base de mantenimiento económico de los Centros Públicos sigue siendo, en 1992, el Estado central y en poco nivel las otras Administraciones. La presencia de las empresas y del capital extranjero en la $\mathrm{I}+\mathrm{D}$ de los Centros Públicos sigue siendo muy escasa, lo que sugiere que aún perdura la desconexión entre ese tipo de centros investigadores y los sectores privados (gráfico 3.17). Ingeniería y Tecnología, junto a Ciencias Agrarias, son las disciplinas predominantes en este sector de Administraciones Públicas (gráfico 3.18). La investigación aplicada es mayoritaria en todos los campos o disciplinas científicos, escasa la investigación fundamental o básica, manteniéndose en el intermedio el llamado «desarrollo experimental» (gráfico 3.18).

En España lo que más predomina es la investigación aplicada y el desarrollo experimental, lo que implica una dependencia acusada de investigación básica extranjera y una misma debilidad en la propia investigación aplicada, menos «fecundada» por la básica.

En el sector de los Centros de Enseñanza Superior ha crecido porcentualmente el gasto en todas las disciplinas, lo que, en buena medida, se debe al incremento de todo el sector. Aquí, considerando los gastos, destacan las Ciencias Exactas y Naturales, así como las Sociales y Humanidades, lo que hace ver que en los Centros de Enseñanza Superior y en los Centros directamente adjudicados al sistema público de investigación la orientación o prioridad de los gastos es diferente (gráfico 3.19).

En el sector de las empresas, comparando lo gastado entre 1983 y 1992 en las distintas ramas de actividad, se aprecia un aumento porcentual en agricultura, manufacturas metálicas y financieras-seguros, aunque en conjunto dentro de este sector es donde menos variaciones se han producido en los últimos años (gráfico 3.20). En el caso de estas empresas, los gastos de investigación se destinan, sobre todo, a la rama de manufacturas metálicas (52\%), otras manufacturas $(7 \%)$, extractivas y químicas $(17 \%)$ y financieras-seguros $(8,4 \%)$, siendo casi inexistente lo dedicado a investigación y desarrollo en agricultura, construcción y comercio, ramas que sin embargo son importantes para las propias empresas (gráfico 3.21); también la mayoría del gasto se va en los gastos 
corrientes y una pequeña parte $(14,6 \%$ ) a gastos de capital, entre los que se cuentan básicamente los dedicados a equipos e instrumental (gráfico 3.22).

Por otra parte, el sector empresas dedica la mayoría de los gastos al desarrollo tecnológico (67\%) y no tanto a la investigación incluso aplicada (26\%), lo que señala la orientación de la $\mathrm{I}+\mathrm{D}$ en este sector (gráfico 3.23). Lo que quizás es más significativo en las empresas es que la mayoría de los fondos para su investigación y desarrollo procede de ellas mismas $(76 \%) \mathrm{y}$, en un porcentaje menor (11\%), de las Administraciones Públicas, especialmente la Administración central (gráfico 3.22), aunque siempre hay que considerar que muchas empresas son también públicas.

En resumen, tanto por el origen de los fondos empleados como por la distribución del gasto en los distintos campos disciplinarios o ramas, se aprecia una orientación diferente en los tres sectores indicados. Las variaciones, algunas significativas, dentro de cada sector (Administración Pública, Enseñanza Superior y Empresas) se explican, sólo en parte, por políticas diferentes de gasto en cada uno de ellos; además, pueden deberse a reajustes internos no bien controlados o a nuevas exigencias socioeconómicas, siendo el fuerte aumento relativo del gasto en la I+D de la Enseñanza Superior el que ha podido hacer variar los porcentajes relativos de los propios campos en los otros dos sectores, especialmente en los campos dependientes de las Administraciones Públicas.

Hay que reseñar también que, después de un notable incremento de los fondos destinados a $\mathrm{I}+\mathrm{D}$ en algunos organismos dependientes de la Administración, en la década de los años ochenta a noventa, posteriormente esos fondos se han estacionado. Tal cosa ha ocurrido en el Consejo Superior de Investigaciones Científicas, que de unos cinco mil millones en 1977 pasó a contar con cuarenta y un mil millones en 1990 , pero a partir de ese año el incremento se moderó mucho, incluso cayó algo en 1991 (gráfico 3.24). Parece que pasado el impulso que se dio a la $\mathrm{I}+\mathrm{D}$ en inversiones al comienzo de los ochenta por mor, en gran parte, de la llamada Ley de la Ciencia, se cayó en un período de estancamiento por las dificultades económicas generales en que entró España y los reajustes de los presupuestos del Estado. Porcentualmente han descendido las aportaciones del propio Estado, incrementándose los ingresos patrimoniales del Consejo (CSIC) (gráfico 3.24). También han descendido los porcentajes de gastos dedicados al personal, pero han aumentado (32\%) los de mantenimiento y, más significativo, el porcentaje de inversiones en construcciones y equipos (21\%) (gráfico 3.25). En los últimos años la distribución de gastos, porcentualmente, según áreas o campos de investigación no ha variado sensiblemente, siendo las Ciencias Sociales, Técnicas Químicas y Técnicas de Alimentos las que consumen menores gastos (gráfico 3.26). Considerando el tipo de personal, el Consejo mantiene los porcentajes relativos, sólo con ligeras variaciones en lo referido a personal laboral, en formación y el denominado personal funcionario, habiendo crecido algo, el último año constatado de 1993, el personal contratado (gráfico 3.27). En conjunto, el personal total del Consejo Superior de Investigaciones Científicas ha descendido (índice 93), sobre todo 
en la década de los años noventa, debido al descenso del personal auxiliar, ayudante o "intermedio" (índice 86), así como el denominado personal laboral (índice 59), pero en el mismo período (1977-1993) se ha incrementado el personal investigador (índice 159), lo que ha repercutido en un ligero aumento del personal calificado como "funcionario» (índice 109) y, a la par, ha crecido la ratio del personal investigador al intermedio, es decir, más investigadores con menos auxiliares (ratio 0,36 y 1,2 en 1993). Para determinar el tipo más concreto de personal que se incluye en las categorías usadas puede verse la nota que acompaña a los datos en el gráfico 3.28. Así, el Consejo perdió personal y aumentó su carácter funcionarial, lo que pudo deberse al traspaso de personal a las Autonomías, a una reconversión interna del personal en el sentido ya indicado o a una baja neta del propio personal; lo cierto es que, desde ese punto de vista, el Consejo (CSIC) ha visto en parte mermada su importancia. No sabemos si habrá ocurrido igual en otros Organismos Públicos de Investigación (OPI) dependientes de otros Ministerios que, según un Real Decreto de 7 de mayo de 1996 (755/1996), en su disposición final tercera señala que el Gobierno en el plazo de seis meses y «en uso, asimismo, de las facultades conferidas por el artículo 76 de la Ley 42/1994, de 30 de diciembre, refundirá en el Consejo Superior de Investigaciones Científicas aquellos Organismos autónomos, adscritos a los diferentes departamentos ministeriales, que desarrollen actividades de investigación o experimentación» (BOE, 8 de mayo de 1996). En cuanto a la distribución del personal del CSIC por sectores de actividades, la variación en los últimos años ha sido pequeña (gráfico 3.29), aunque variará en los próximos años si se realiza la refundición señalada de otros organismos en el mismo Consejo y, de ser así, todo él experimentará una considerable modificación.

Considerando otra perspectiva e introduciendo una terminología discutida, pero aún operante, observamos que en 1992 la mayor parte del gasto se dedicó al desarrollo y la investigación aplicada: el $82 \%$ en los centros de las Administraciones Públicas y el $96 \%$ en los de empresas, lo que ocurre desde hace años en el conjunto de la I+D española (gráficos 3.30 y 3.31). Sólo en dos campos o disciplinas científicos predomina el gasto en investigación bási$\mathrm{ca}$, por la misma índole de esas materias: ciencias exactas y naturales, así como sociales y humanidades (gráfico 3.32).

La dependencia tecnológica de España ha sido una constante ya detectada en trabajos anteriores y, en general, un hecho asumido. El interés se ha centrado más bien en la dimensión del desfase entre las importaciones y exportaciones, entre los pagos y los ingresos por la tecnología extranjera y nacional. Aunque sólo permiten una aproximación, las cifras de la balanza de pagos por transferencias tecnológicas facilitan la expresión de ese desfase. Considerando los diez últimos años, para los que contamos con datos, podemos ver que las exportaciones españolas de tecnología, tanto en asistencia técnica y royalties como en derechos de autores, han ido creciendo, multiplicándose por más de tres en esa década, aunque sufrieron un descenso en los años 86 a 87 , que fue 
ya superado en el año 1989. Los pagos que organismos y empresas españoles realizaron por compras de tecnología también han crecido en ese período, observándose un salto significativo el año 81 al 82, descendió algo en 1984, pero en 1987 los gastos por transferencia tecnológica claramente se dispararon al alza, continuando esa tendencia los años posteriores, al menos hasta 1990. Lo más significativo es que el balance negativo para España se ha ido incrementando, siendo cada año más amplio el desfase desfavorable entre pagos e ingresos. España, en 1990, era casi veinte veces más dependiente, por su transferencia de tecnología, que lo era en 1979 (gráfico 3.33).

\section{GRÁFICO 3.1}

Gastos totales intramuros en $I+D$. Pesetas constantes de $1992\left(^{*}\right)$. España, 1970-1994

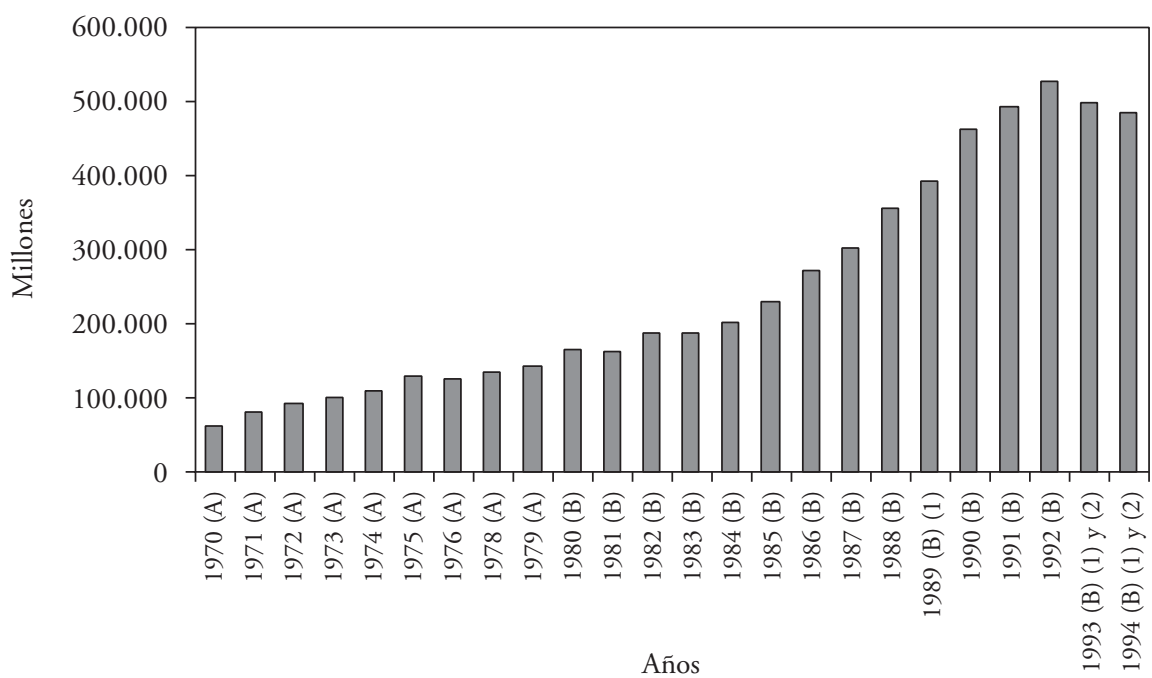

$\left(^{*}\right)$ Deflectada la Serie con el IPC en base $1992=100$ tomado en diciembre de cada año.

Ejemplo: Año $1988 \rightarrow \mathrm{IPC}_{\text {DIC (BASE 92) }}=80,742 \rightarrow \frac{287.689 \times 100}{80,742}=356.306,5$

(1) Incluye Sector IPSFL.

(2) Proyecciones.

Fuentes: (A) Estadistica sobre las Actividades en Investigación Cientifica y Desarrollo Tecnológico (I+D). Años 1978-1981, INE, Madrid, 1985.

(B) Estadistica sobre las Actividades en Investigación Cientifica y Desarrollo Tecnológico (I+D). Año 1992, INE, Madrid, 1993. 


\section{GRÁFICO 3.2}

Gastos totales intramuros en $I+D$ en relación con el PIB. España, 1970-1993

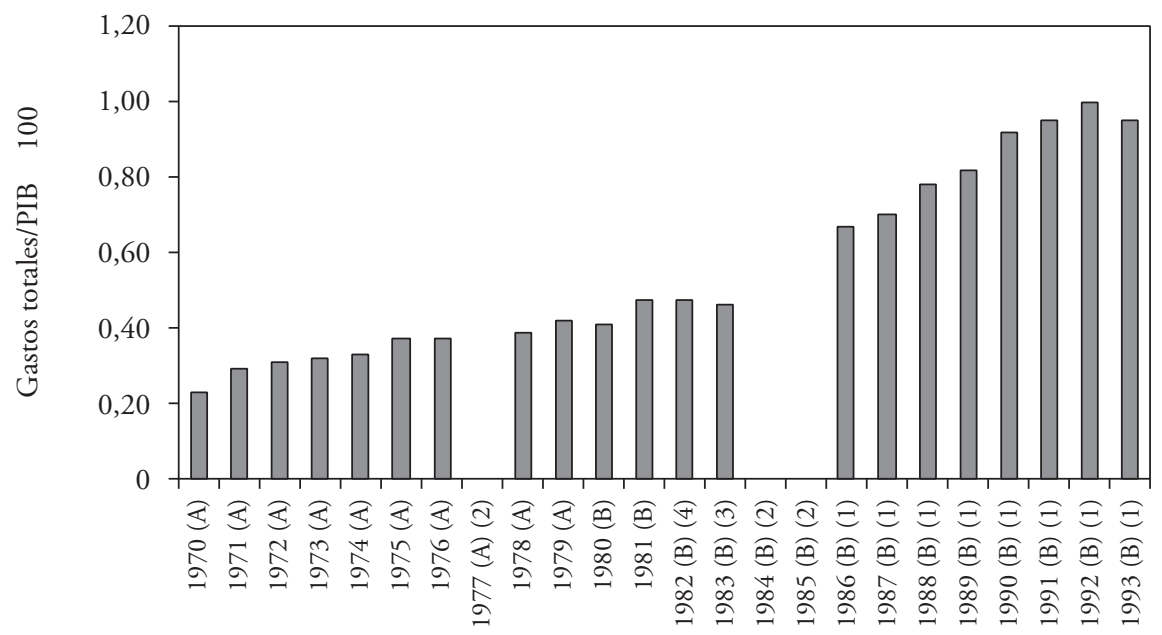

Años

(1) Incluye Sector Instituciones Privadas sin Fines de Lucro (IPSFL).

(2) Datos no disponibles.

(3) Datos avance.

(4) Datos provisionales.

Fuentes: (A) Estadistica sobre las Actividades en Investigación Cientifica y Desarrollo Tecnológico (I+D). Años 1978-1981, INE, Madrid, 1985.

(B) Estadistica sobre las Actividades en Investigación Cientifica y Desarrollo Tecnológico (I+D). Año 1992, INE, Madrid, 1993. 


\section{GRÁFICO 3.3}

Pagos por compra de tecnología y gastos en $I+D$ en relación al PIB, según paises, 1990

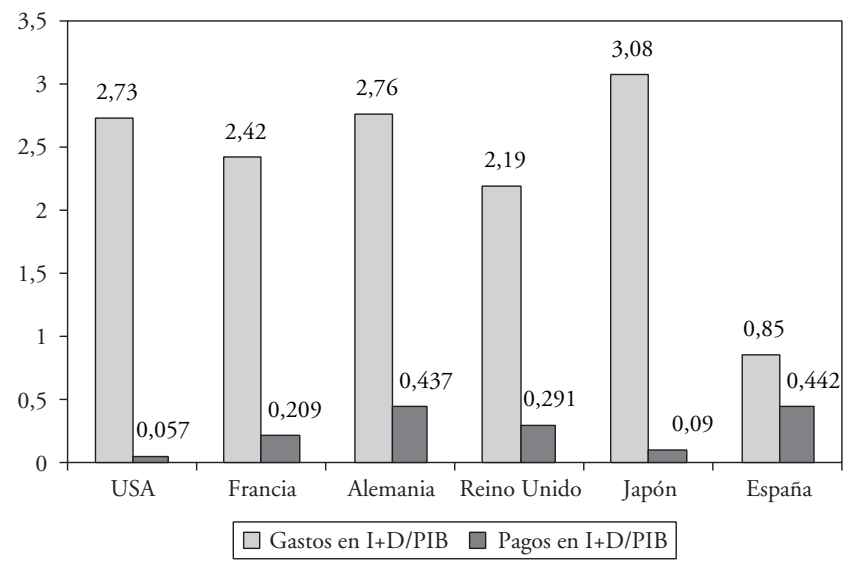

Pagos por compra de tecnología/PIB =

Balanza de pagos tecnología ${ }_{\text {pais }}$ (millones moneda nacional) $\mathrm{PIB}_{\text {pais }}$ (millones moneda nacional)

Fuente: OECD. EAS (STIU DATABASE). Noviembre $1993 \rightarrow$ Obtenido de la CEOE.

\section{GRÁFICO 3.4}

Porcentajes de gastos intramuros totales en $I+D$, por oriegen de fondos

(millones pesetas corrientes). España, 1980-1992

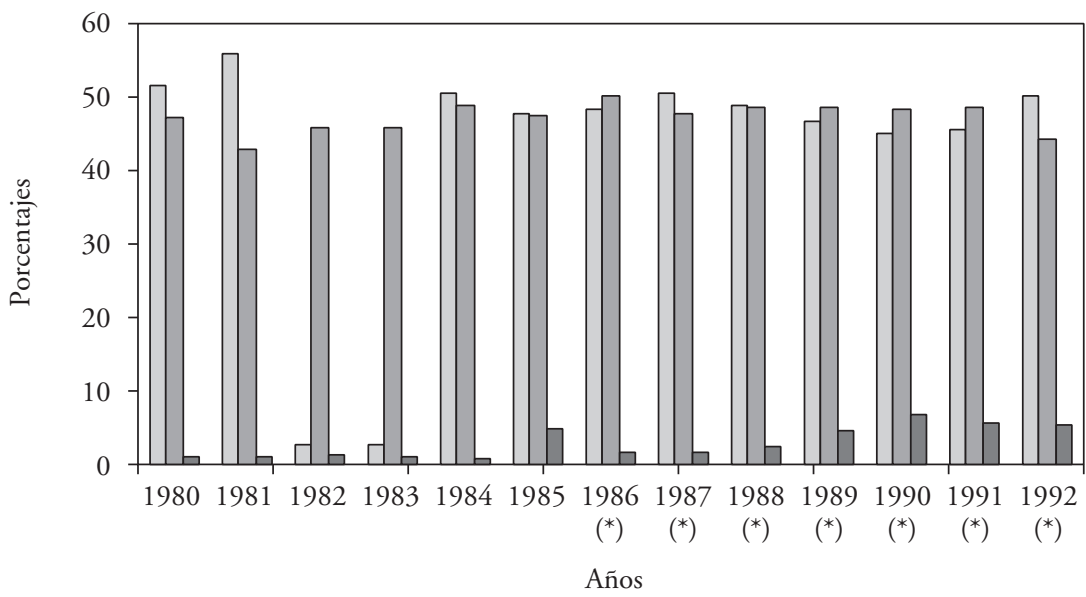

\section{Sector Público $\square$ Sector Privado $\quad \square$ Extranjero}

$\left(^{*}\right)$ Incluye Sector Instituciones Privadas sin Fines de Lucro (IPSFL).

Fuente: Estadistica sobre las Actividades en I+D. Año 1992, INE, Madrid, 1993. 


\section{GRÁFICO 3.5}

Origen de los fondos (intramuros) invertidos en $I+D$ por años (millones de pesetas). España, 1974 y 1992

\section{4}

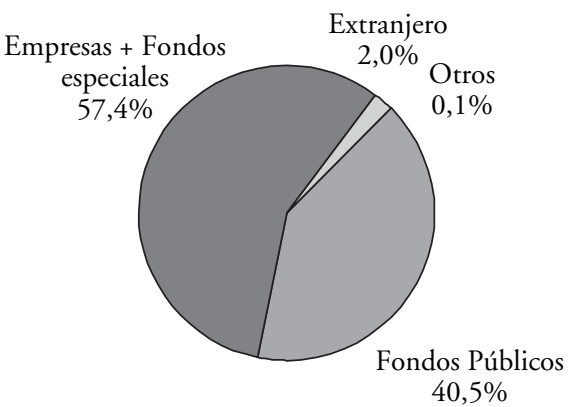

1992

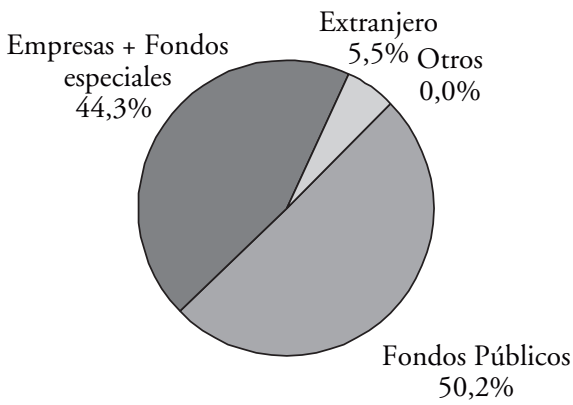

Fuentes: (1) Estadistica sobre las Actividades en I+D. Años 1984-1985, INE, Madrid, 1988.

(2) Estadistica sobre las Actividades en I+D. Año 1992, INE, Madrid, 1993.

\section{GRÁFICO 3.6}

Origen de fondos (intramuros) invertidos en $I+D$ en pesetas constantes de 1992 (porcentajes)

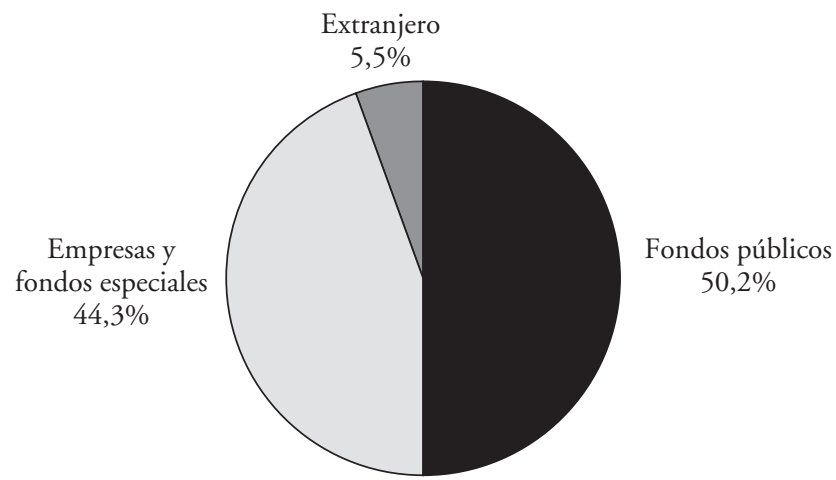

Las series han sido deflectadas con IPC base $1992 \oplus 100$ :

$$
\begin{array}{l|l}
\mathrm{IPC}_{1974 \mathrm{DIC}}=14,558 & \mathrm{IPC}_{1985 \mathrm{DIC}}=67,371 \\
\mathrm{IPC}_{1975 \mathrm{DIC}}=16,610 & \mathrm{IPC}_{1988 \mathrm{DIC}}=80,742 \\
\mathrm{IPC}_{1984 \mathrm{DIC}}=62,278 & \mathrm{IPC}_{1990 \mathrm{DIC}}=91,955
\end{array}
$$$$
\mathrm{IPC}_{1992 \text { DIC }}=12,227
$$

FUENTES: (1) Estadística sobre las Actividades en I+D. Años 1984-1985, INE, Madrid, 1988.

(2) Estadística sobre las Actividades en I+D. Año 1992, INE, Madrid, 1993. 


\section{GRÁFICO 3.7}

Origen y uso de los fondos en $I+D$ por sectores de ejecución. España, año 1992 (porcentajes)

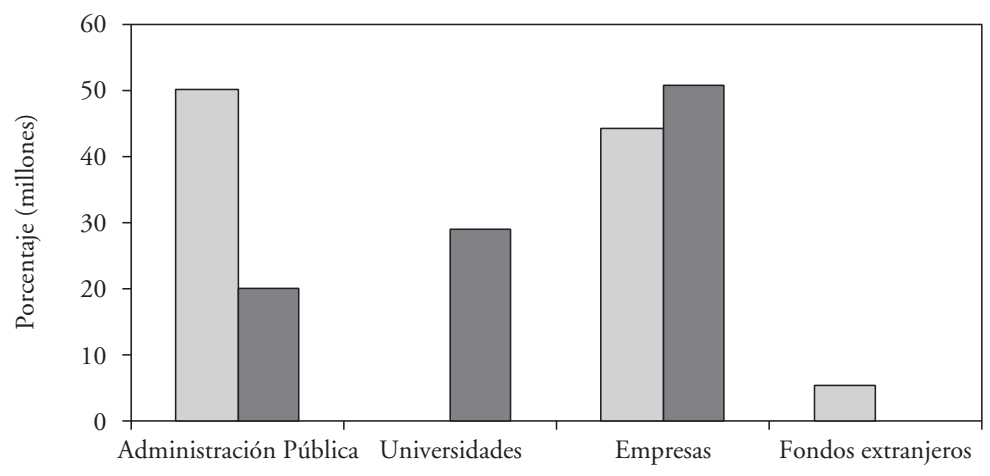

Sectores de ejecución

$\square$ Origen fondos $\square$ Gastos totales

Fuente: Estadistica sobre las Actividades en I+D. Año 1992, INE, Madrid, 1993.

\section{GRÁFICO 3.8}

Gastos intramuros en I+D: corrientes a total y años (millones de pesetas constantes). España, 1970-1992

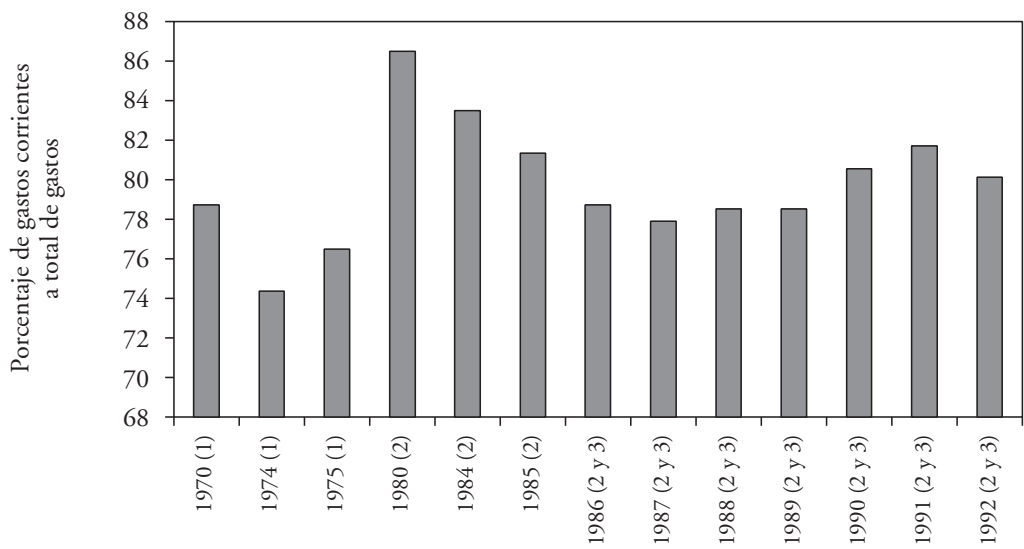

Años

NoTA: (3) incluye Sector IPSFL.

Fuentes: (1) Estadistica sobre las Actividades en I+D. Años 1978-1981 y 1984-1985, INE, Madrid, 1988.

(2) Estadística sobre las Actividades en I+D. Año 1992, INE, Madrid, 1993. 


\section{GRÁFICO 3.9}

Gastos intramuros en $I+D$ según tipo de gasto y sectores de ejecución (millones de pesetas) (*). España, 1992

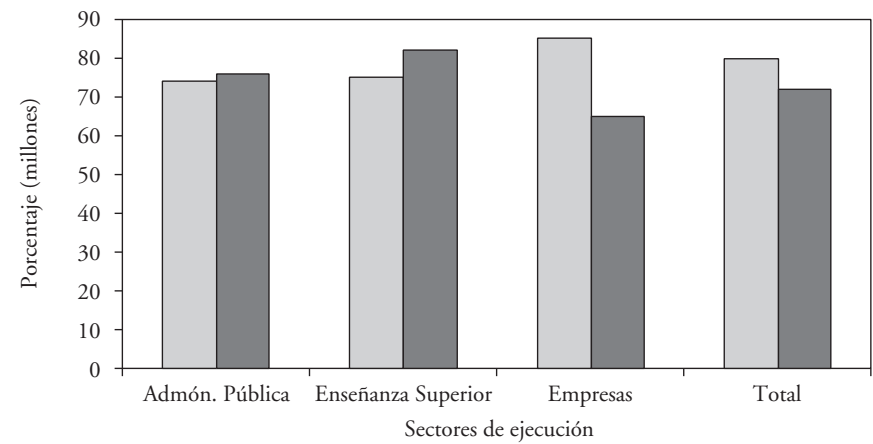

$\square$ gastos corrientes sobre el total de gastos

$\square$ de retribuciones sobre los gastos corrientes

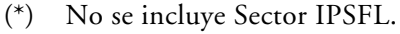

Fuente: Estadistica sobre las Actividades en I+D. Año 1992, INE, Madrid, 1993.

\section{GRÁFICO 3.10}

Distribución del total de gastos intramuros según tipo de gasto y sectores de ejecución.

$$
\text { España, } 1992
$$

Gastos corrientes

$\%$ del total de gastos intramuros
Gastos capital

$\%$ del total de gastos intramuros

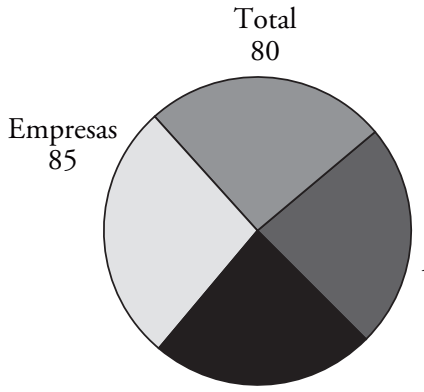

Enseñanza Superior 75

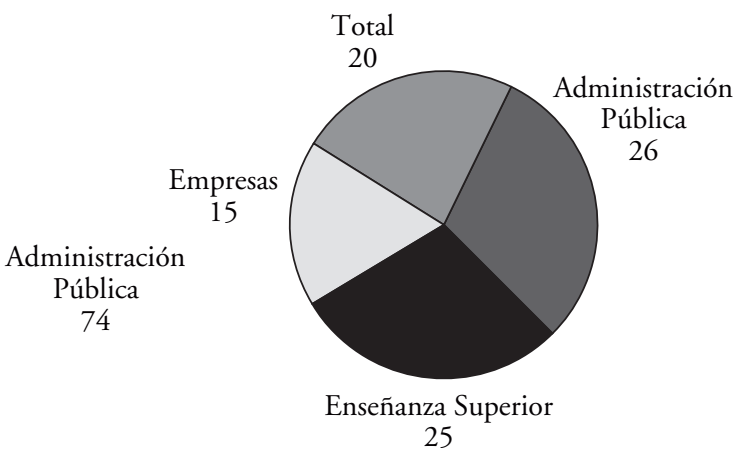

No se incluye Sector IPSFL.

Fuente: Estadistica sobre las Actividades en I+D. Año 1992, INE, Madrid, 1993. 


\section{GRÁFICO 3.11}

Gastos totales intramuros en actividades de I+D por sectores de ejecución, 1994

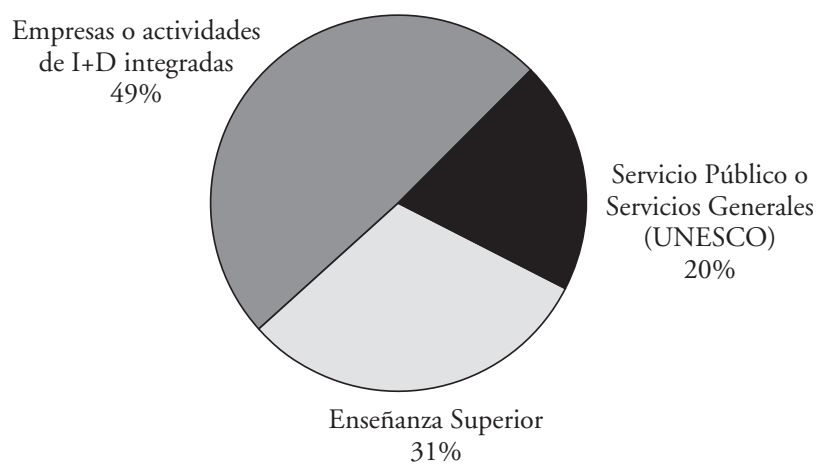

Incluye Sector IPSFL (Instituciones Privadas Sin Fines de Lucro).

Proyecciones.

En el Anuario de la UNESCO 1994 se denominan Servicios Generales.

En el Anuario de la UNESCO 1994 se denominan «Actividades de I+D integradas».

Fuentes: (1) Estadística sobre las Actividades en I+D. Años 1978-1981, INE, Madrid, 1985.

(2) Estadistica sobre las Actividades en I+D. Año 1992, INE, Madrid, 1993.

\section{GRÁFICO 3.12}

Gastos total $(*)$ por sectores de ejecución y disciplinas científicas. España, 1976

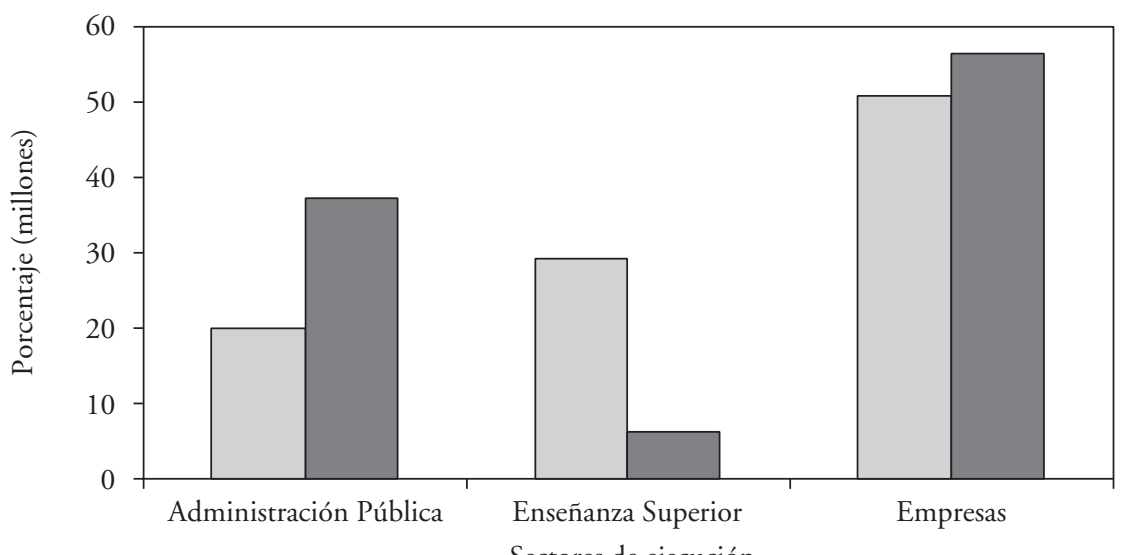

Sectores de ejecución

$$
1992 \square 1976
$$

${ }^{*}$ Gastos intramuros.

Fuente: Estadistica sobre las Actividades en I+D. Año 1992, INE, Madrid, 1993. 


\section{GRÁFICO 3.13}

Gastos intramuros en $I+D$ por sectores de ejecución (en millones de pesetas corrientes y constantes de 1992) $\left(^{*}\right)$. España, 1992

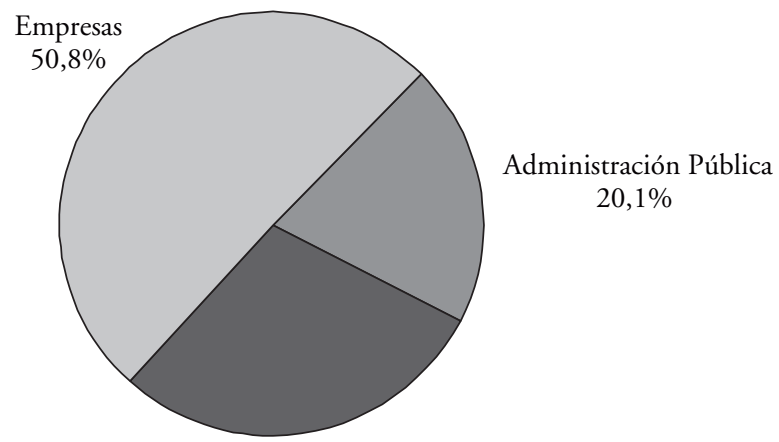

Enseñanza Superior

$29,1 \%$

$\left(^{*}\right)$ La serie ha sido deflactada con el IPC en base $1992=100$ tomado en diciembre de cada año. Fuente: Estadistica sobre las Actividades en I+D. Año 1992, INE, Madrid, 1993.

\section{GRÁFICO 3.14}

Gastos intramuros en $I+D$ de la Administración Pública por disciplina cientifica (porcentaje), 1983 y 1992

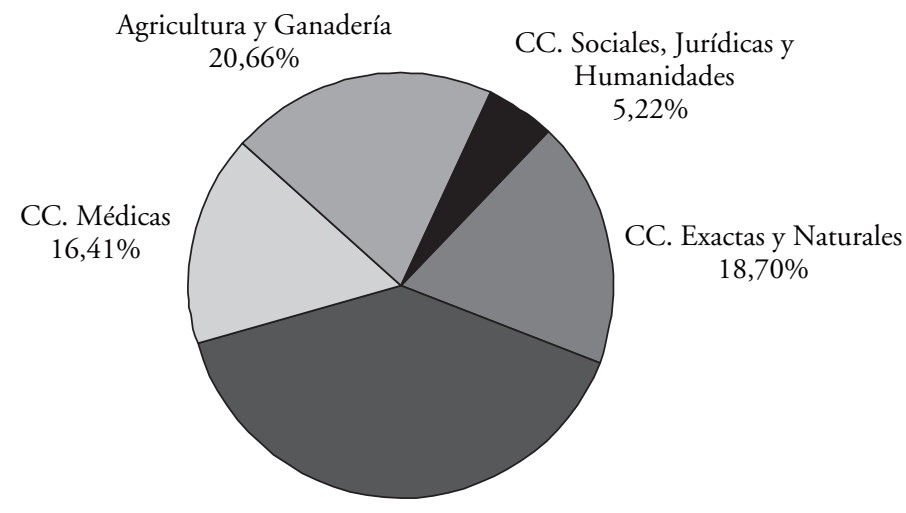

Ingeniería y Tecnología

39,01\%

FUENTE: Estadistica sobre las Actividades en I+D. Años 1978-1981, INE, Madrid, 1985. 


\section{GRÁFICO 3.15}

Gastos de la Administración Pública en I+D por personal y disciplina cientifica. Porcentajes. España, $1992(*)$

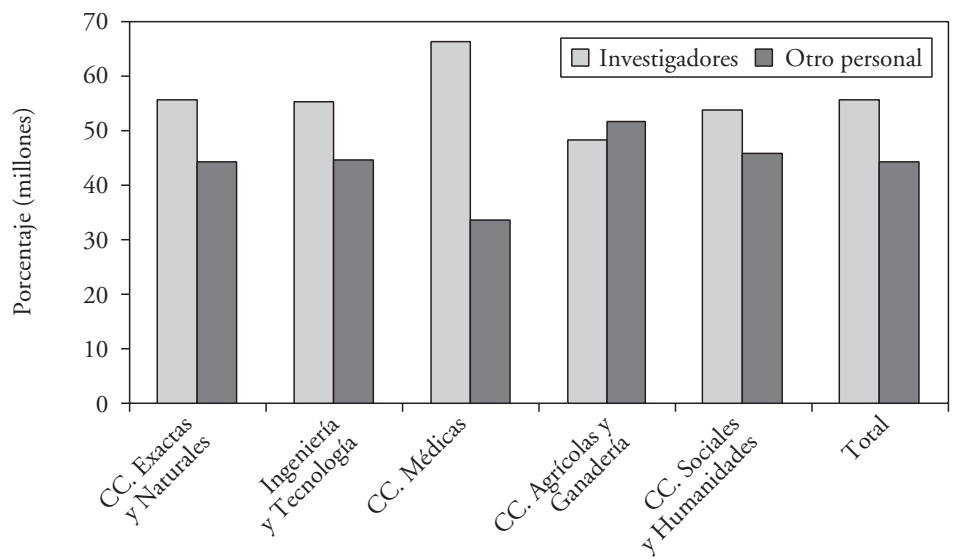

Disciplina científica

(*) Gastos = Retribuciones de personal incluidas dentro de la partida de gastos corrientes.

FuENTE: Estadistica sobre las Actividades en I+D. Año 1992, INE, Madrid, 1993.

\section{GRÁFICO 3.16}

Administración Pública, 1992. Gastos intramuros totales en actividades de $I+D$, según su tipo y por campo o disciplina cientifica (miles pesetas)

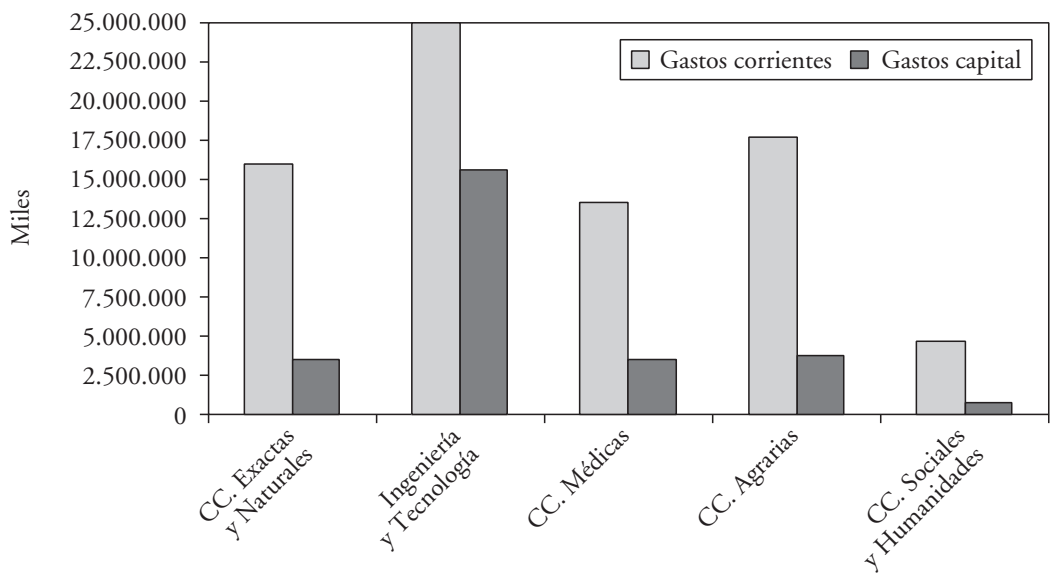

Campo o disciplina científica

FUENTE: Estadistica sobre las Actividades en I+D. Año 1992, INE, Madrid, 1993. 


\section{GRÁFICO 3.17}

Gastos intramuros totales en actividades de $I+D$, según el origen de los fondos y por campo o disciplina científicos (miles pesetas). Administración Pública, 1992

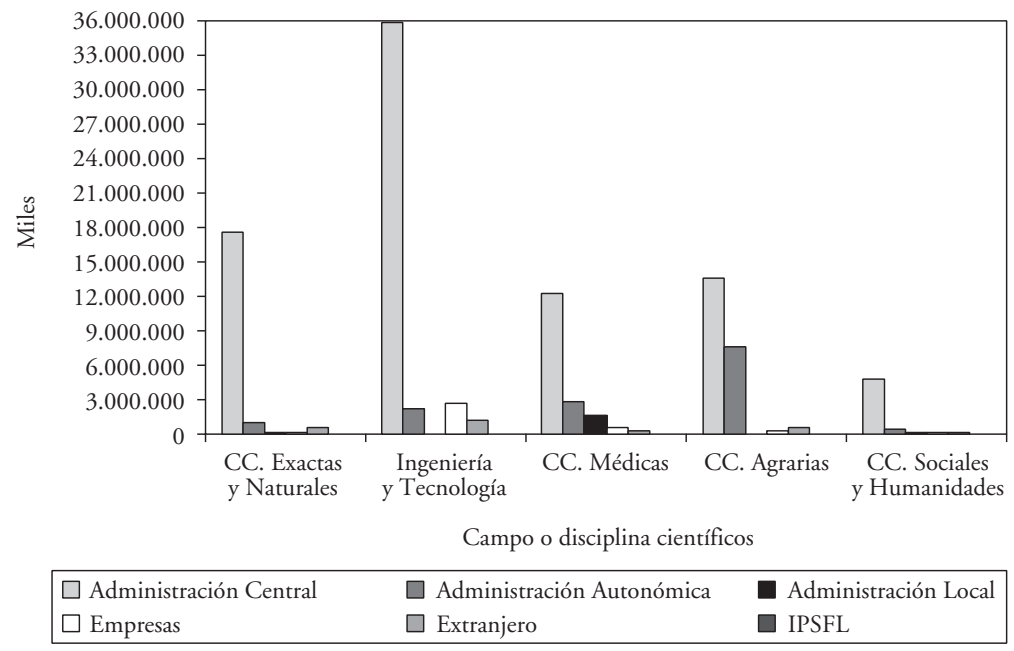

Fuente: Estadistica sobre las Actividades en I+D. Año 1992, INE, Madrid, 1993.

\section{GRÁFICO 3.18}

Gastos intramuros corrientes en actividades de $I+D$, según tipo de invetigación y por campo o disciplina científicos (miles pesetas). Administración Pública, 1992

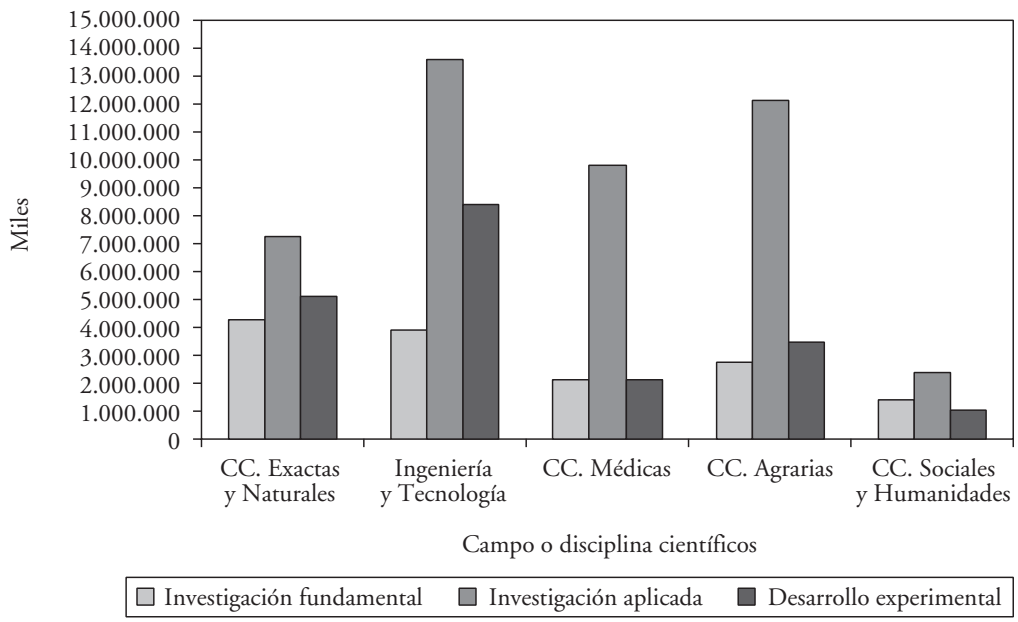

Fuente: Estadistica sobre las Actividades en I+D. Año 1992, INE, Madrid, 1993. 


\section{GRÁFICO 3.19}

Gastos intramuros totales en $I+D$, clasificados según el tipo de gasto y por campo o disciplina científicos (miles pesetas). Enseñanza Superior, 1992

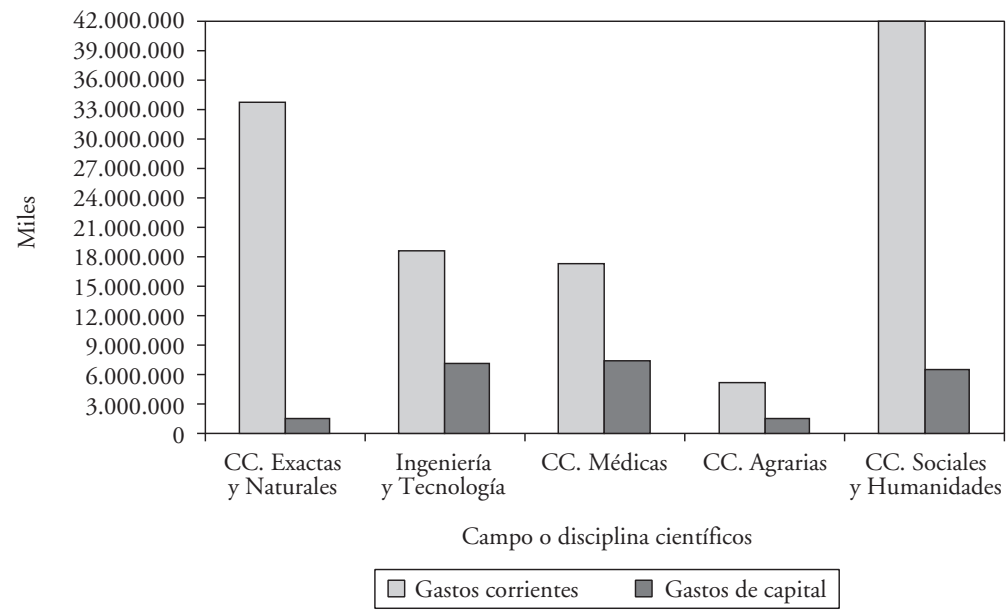

FuENTE: Estadistica sobre las Actividades en I+D. Año 1992, INE, Madrid, 1993.

\section{GRÁFICO 3.20}

Gastos intramuros en $I+D$ de las empresas, por ramas de actividad (porcentaje). Enseñanza Superior, 1983 y 1992

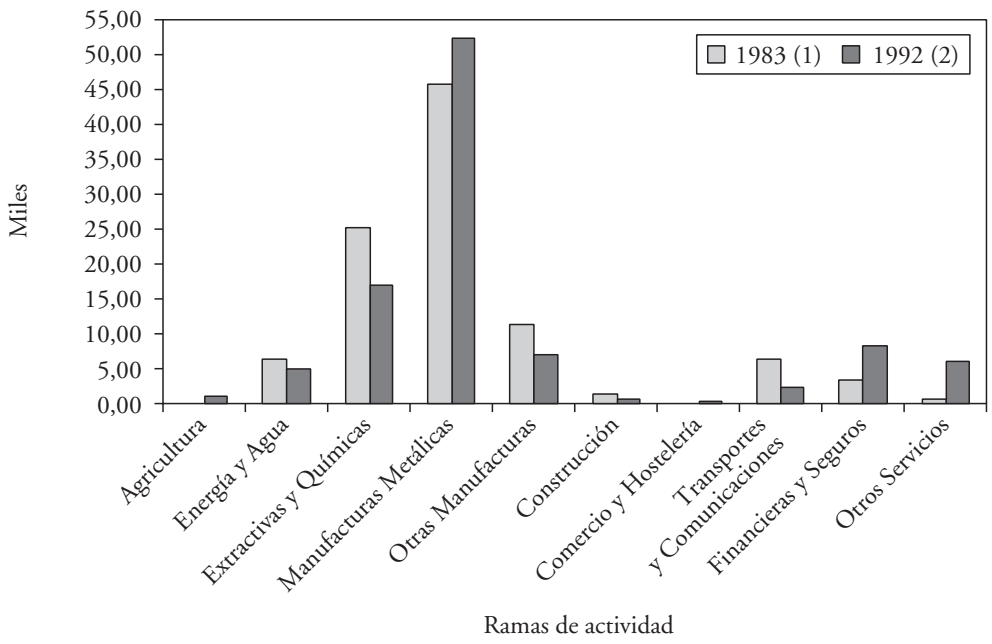

Fuentes: (1) Estadistica sobre las Actividades en I+D. Años 1978-1981, INE, Madrid, 1985.

(2) Estadistica sobre las Actividades en I+D. Año 1992, INE, Madrid, 1993. 


\section{GRÁFICO 3.21}

Gastos intramuros de $I+D$ en actividades, según su clase y rama de actividad económica (miles pesetas). Empresas, 1992

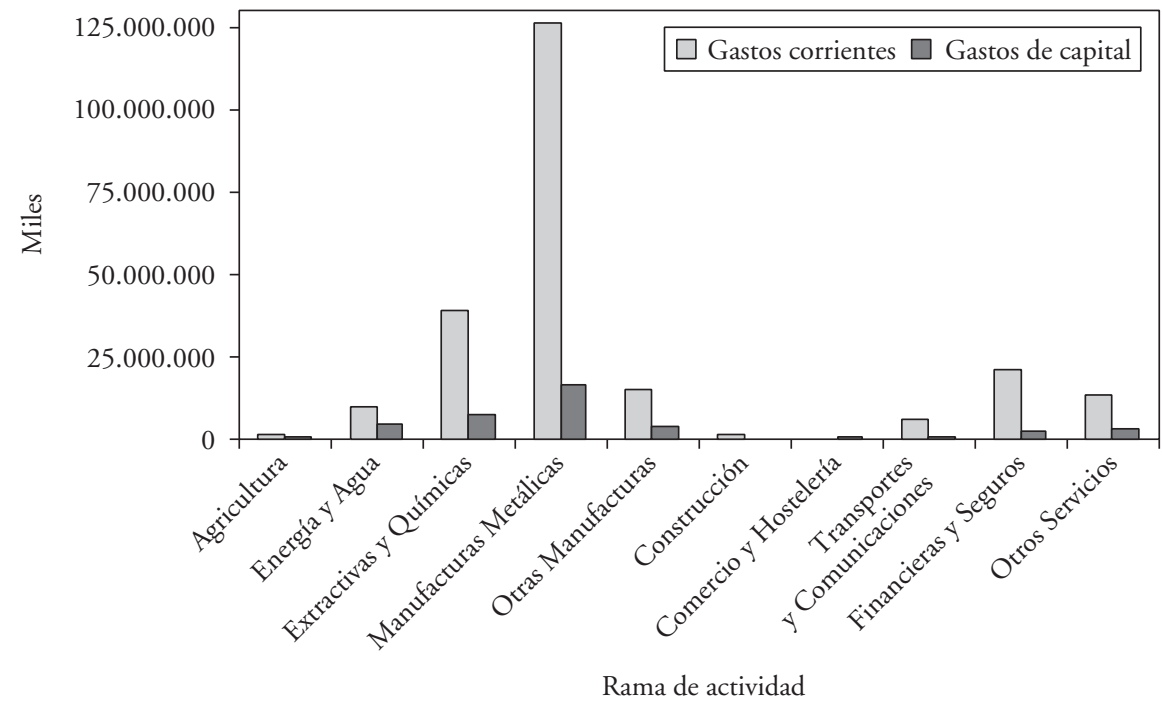

FUENTE: Estadistica sobre las Actividades en I+D. Año 1992, INE, Madrid, 1993.

\section{GRÁFICO 3.22}

Sector empresas. Gastos intramuros en actividades de $I+D$ según origen de fondos y rama de actividad económica. Año 1992

De otras empresas

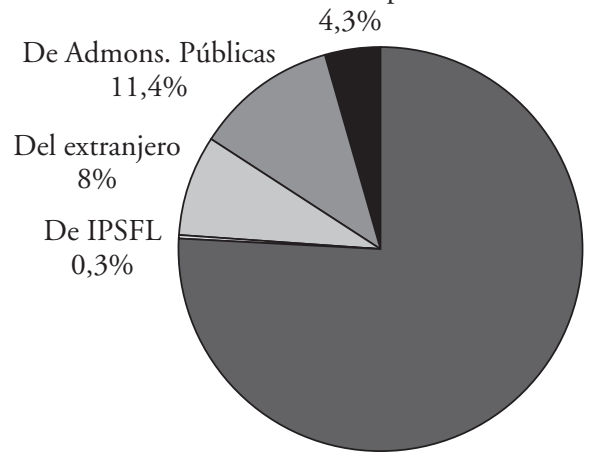

Fondos propios

$76 \%$

IPSFL: Instituciones Privadas sin Fines de Lucro.

FuENTE: Estadistica sobre las Actividades en I + D. Año 1992, INE, Madrid, 1993. 


\section{GRÁFICO 3.23}

Gastos intramuros corrientes en actividades $I+D$, según tipo de investigación y rama de actividad económica (miles pesetas). Empresas

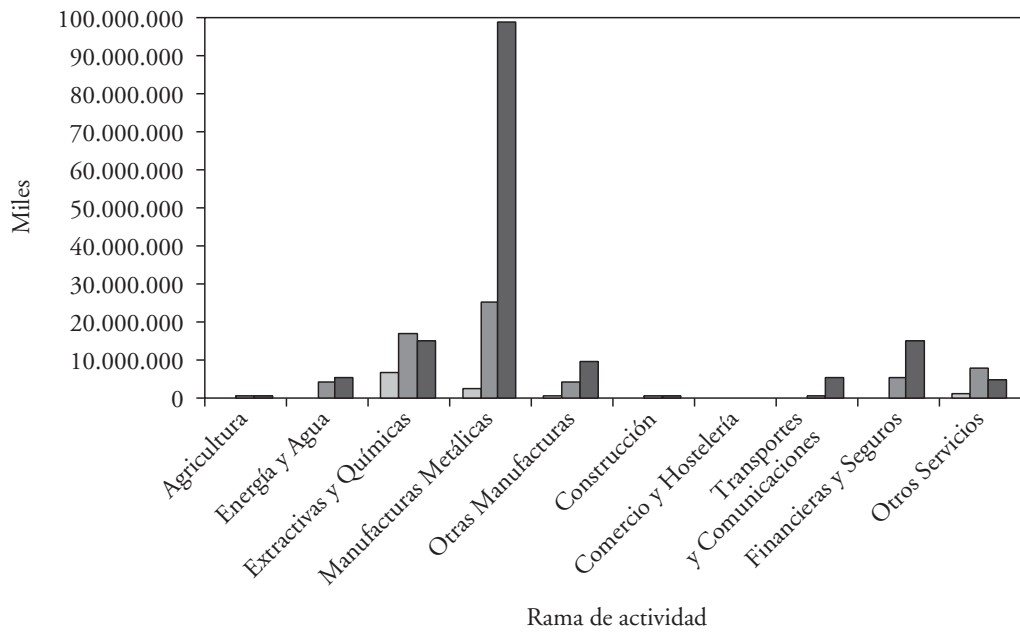

$\square$ Investigación Fundamental $\square$ Investigación Aplicada $\quad \square$ Desarrollo Tecnológico

Fuente: Estadistica sobre las Actividades en I+D. Año 1992, INE, Madrid, 1993.

GRÁFICO 3.24

Origen de los Fondos. Años 1977-1993 (porcentaje). CSIC

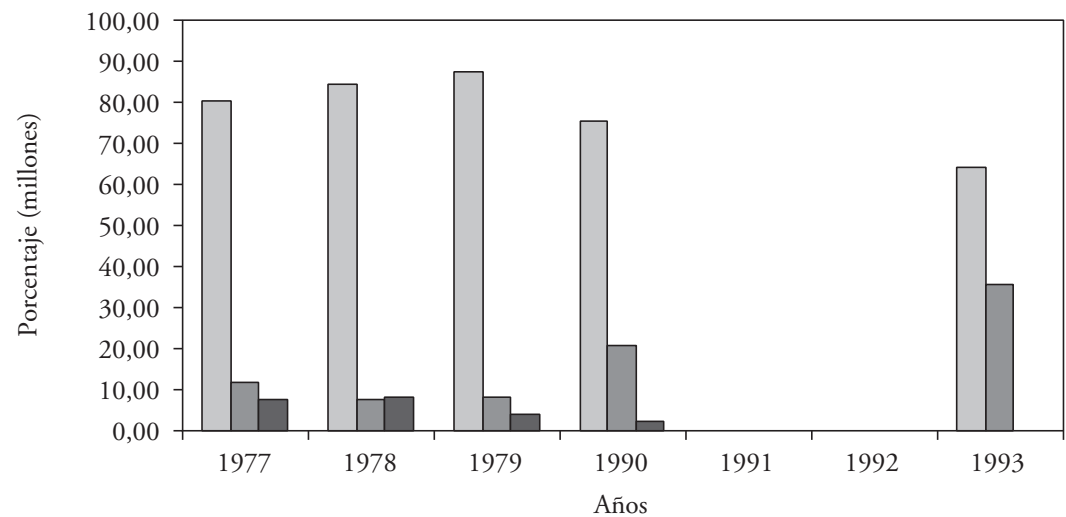

Aportación Estado $\square$ Ingresos Patrimoniales $\quad \square$ Remanentes

NotA: No aparecen estos datos en las Memorias correspondientes del CSIC.

Fuente: Memorias del CSIC, años 1990, 1991, 1992 y 1993. 


\section{GRÁFICO 3.25}

Distribución del gasto por sectores. Años 1977-1993 (porcentaje). CSIC

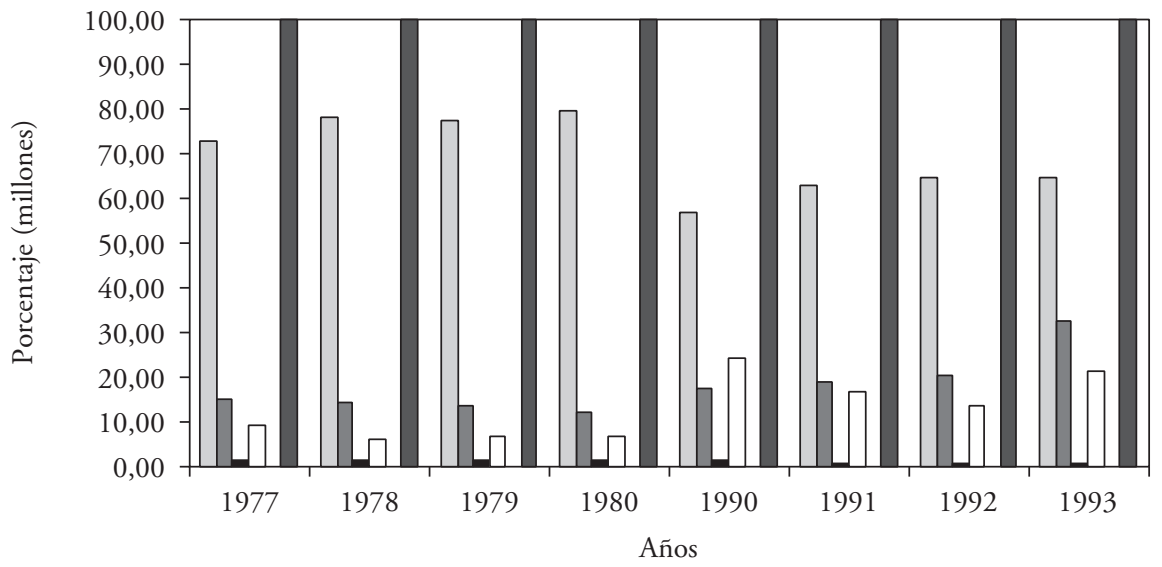

\begin{tabular}{|lrr|}
\hline$\square$ Personal & $\square$ Mantenimiento & Subvenciones \\
$\square$ Invs. en construcciones y equipo $\quad \square$ Gastos varios & $\square$ Porcentaje
\end{tabular}

NotA: Los datos de 1993 vienen incorrectos en la propia Memoria (no suman 100\%).

Fuente: Memorias del CSIC, años 1990, 1991, 1992 y 1993.

\section{GRÁFICO 3.26}

Distribución del gasto según áreas cientifico-técnicas. Año 1993. CSIC. Porcentajes

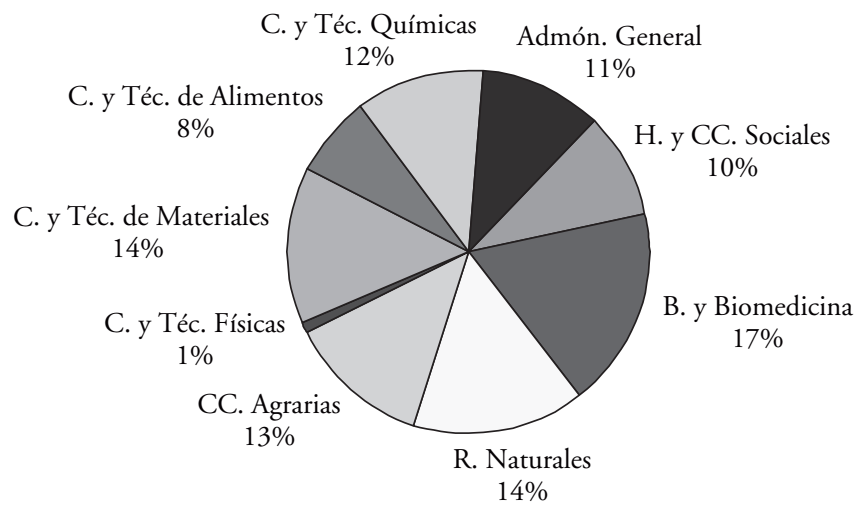

FUENTE: Memoria CSIC, 1992. 


\section{GRÁFICO 3.27}

Distribución del gasto de personal según categoría administrativa para 1992 y 1993.

\section{CSIC}

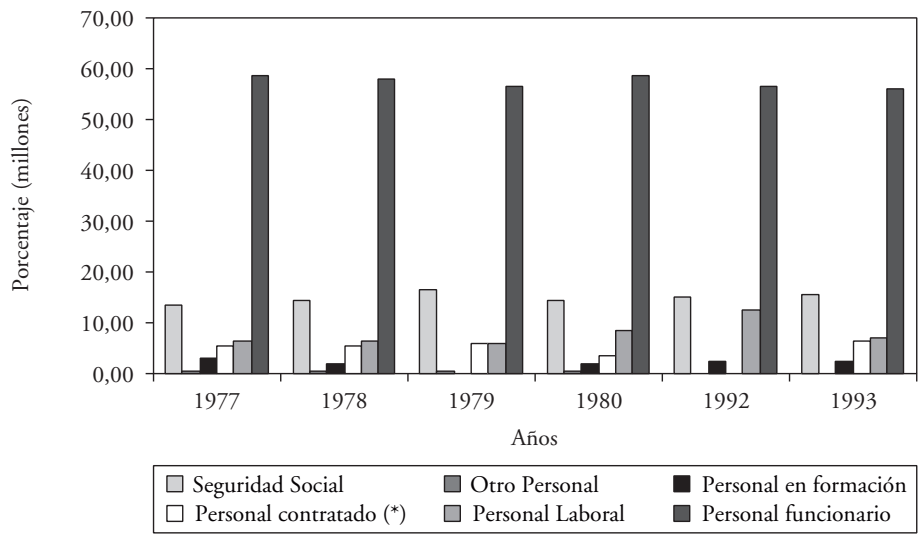

Notas: Incluye el Personal laboral contratado y el Personal con contrato específico.

$\left(^{*}\right)$ Personal Funcionario, que es el 79\% del total: se lleva el 64,10\% + Seg. Social.

Fuente: Memorias del CSIC, 1992 y 1993, y años correspondientes.

\section{GRÁFICO 3.28}

Personal para diferentes años. CSIC, 1977-1993

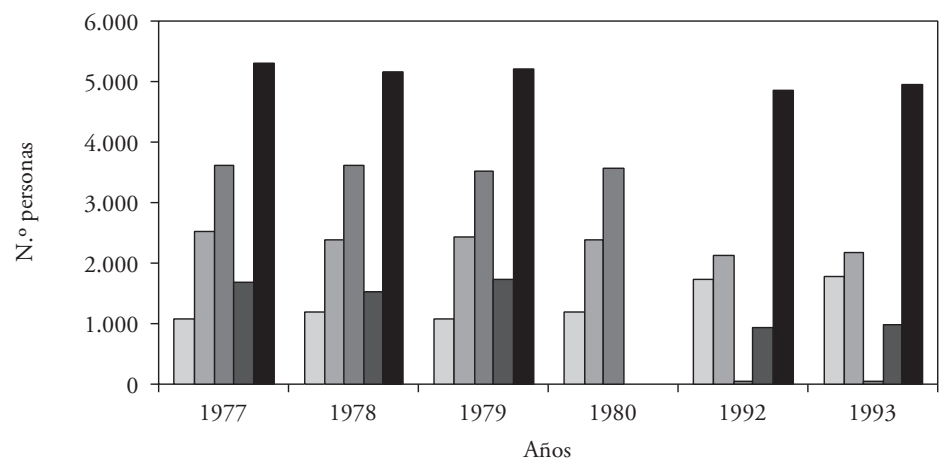

$\begin{array}{ll}\square \text { Personal Investigador (A) }\left(^{*}\right) & \square \text { Personal Intermedio (D) } \\ \square \text { Personal de Carrera - Funcionarios (C=A+D) }\left(^{* *}\right) & \square \text { Personal Laboral (E=B-C) } \\ \square \text { Personal Total (B=A+D+E) }\left({ }^{* *}\right) & \end{array}$

Notas: $\quad\left(^{*}\right)$ A: Personal Investigador. D: Personal Intermedio. C: Personal de Carrera o Funcionario.

$(* *)$ E: Personal Laboral

$(* * *)$ B: Personal Total.

Fuente: Memorias CSIC, 1997-1980 y 1992-1993. 


\section{GRÁFICO 3.29}

\section{Personal total $\left(^{*}\right)$ por sectores de actividades para 1992 y 1993}

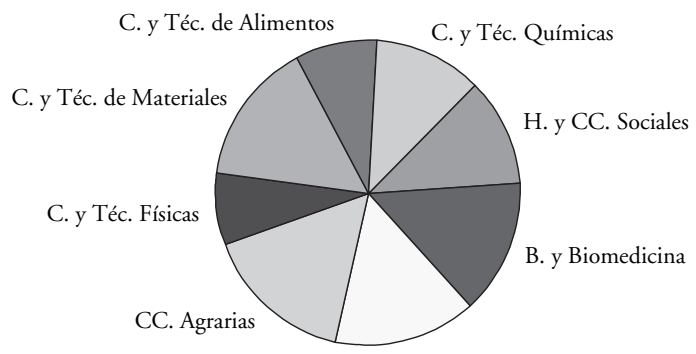

R. Naturales

Notas: No incluye: Personal Universitario (Centros mixtos); Otro personal: Doctores vinculados, Becarios predoctorales, Personal contratado, Otros.

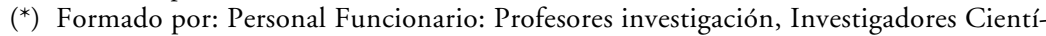
ficos, Colaboradores Científicos, Titulados Superiores Especializados, Titulados Técnicos Especializados, Ayudantes Diplomados de Investigación, Ayudantes de Investigación, Auxiliares de Investigación, Administrativos, Auxiliares Administrativos, Subalternos, otros. Personal Laboral: Nivel I, Nivel II, Nivel III, Nivel IV, Nivel V, Nivel VI, Nivel VII, Nivel VIII, Nivel IX.

FUENTE: Memorias CSIC, 1992 y 1993.

\section{GRÁFICO 3.30}

Gastos intramuros corrientes en $I+D$, por tipo de investigación (millones pesetas corrientes). España, 1970, 1980 y 1992

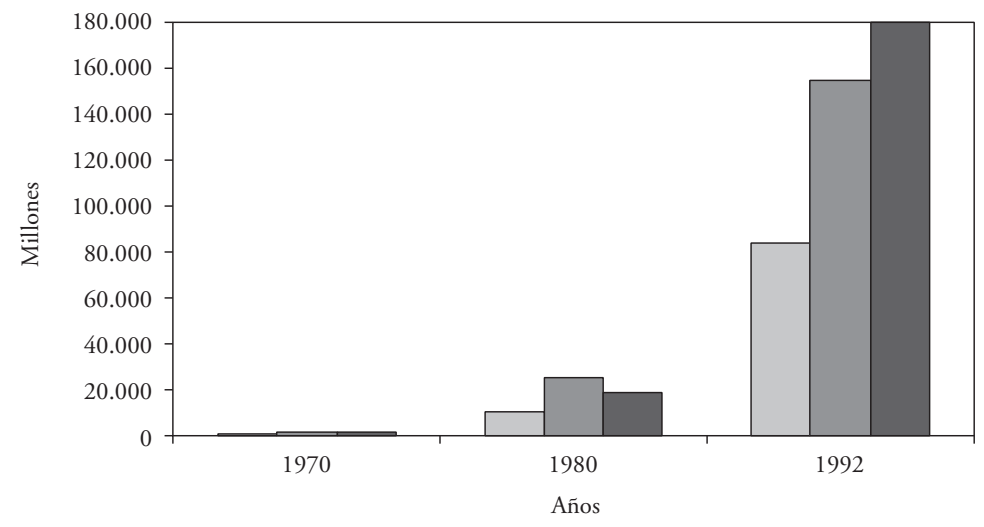

Investigación básica (A)

$\square$ Investigación aplicada (B)

Desarrollo experimental (C)

NoTA: Incluye el Sector IPSFL.

Fuentes: (A) Estadistica sobre las Actividades en I+D. Años 1978-1981, INE, Madrid, 1985.

(B) Estadistica sobre las Actividades en I+D. Año 1992, INE, Madrid, 1993. 


\section{GRÁFICO 3.31}

Distribución porcentual de los gastos intramuros corrientes en $I+D$, por tipo de investigación y sector de ejecución. España, 1992

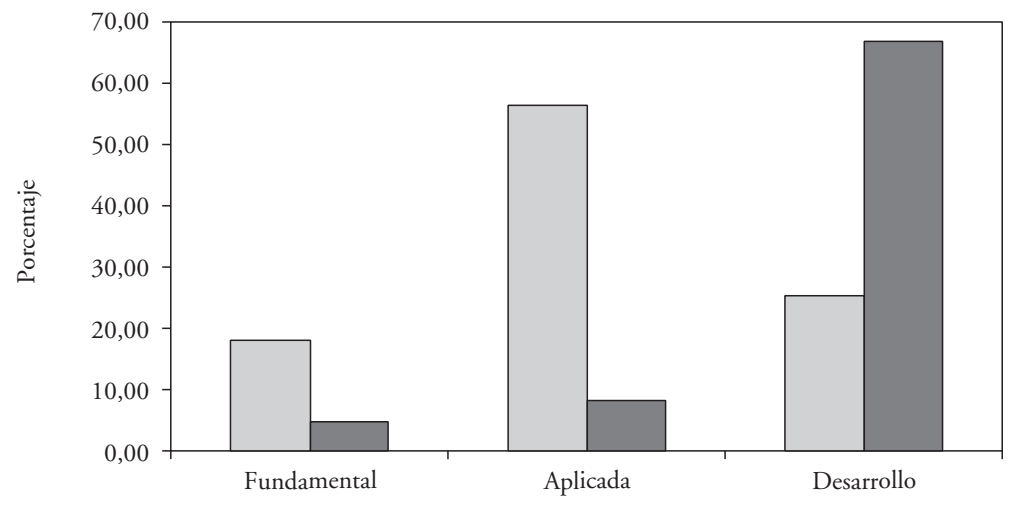

Tipo de investigación

$$
\text { Administraciones Públicas } \square \text { Empresas }
$$

Fuente: Estadistica sobre las Actividades en I+D. Año 1992, INE, Madrid, 1993.

\section{GRÁFICO 3.32}

Gastos intramuros corrientes en $I+D$, según tipo de investigación y por campo o disciplina cientificos (miles pesetas). España, 1992

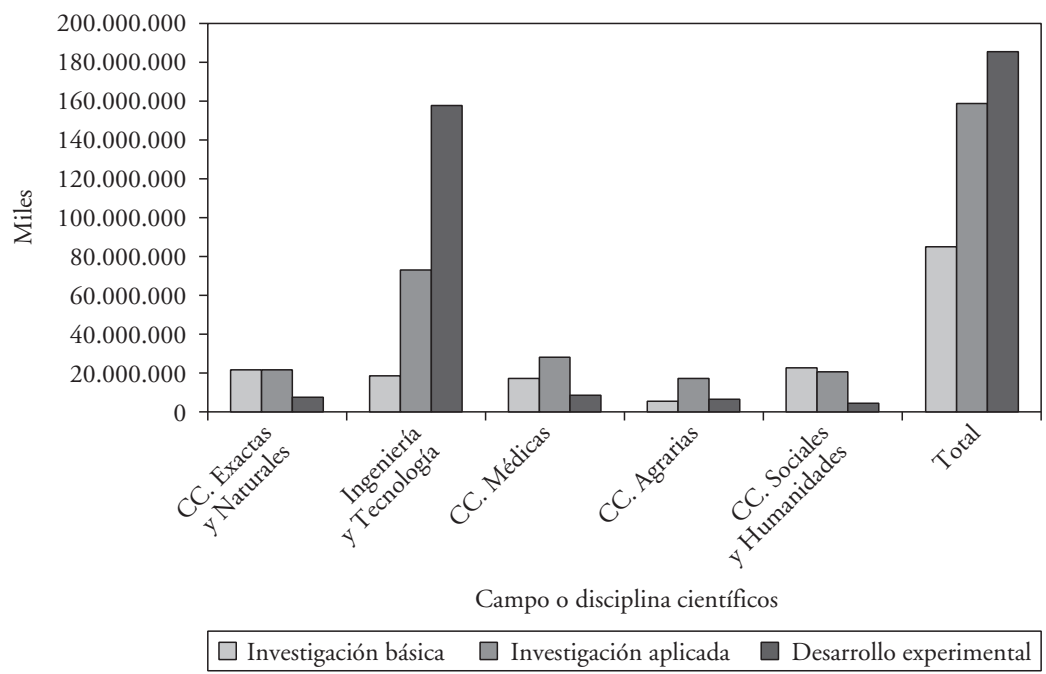

Fuente: Estadistica sobre las Actividades en I+D. Año 1992, INE, Madrid, 1993. 


\section{GRÁFICO 3.33}

Ingresos y pagos por "asistencia técnica y royalties» $y$ "derechos de autor»

(España, 1980-1990)

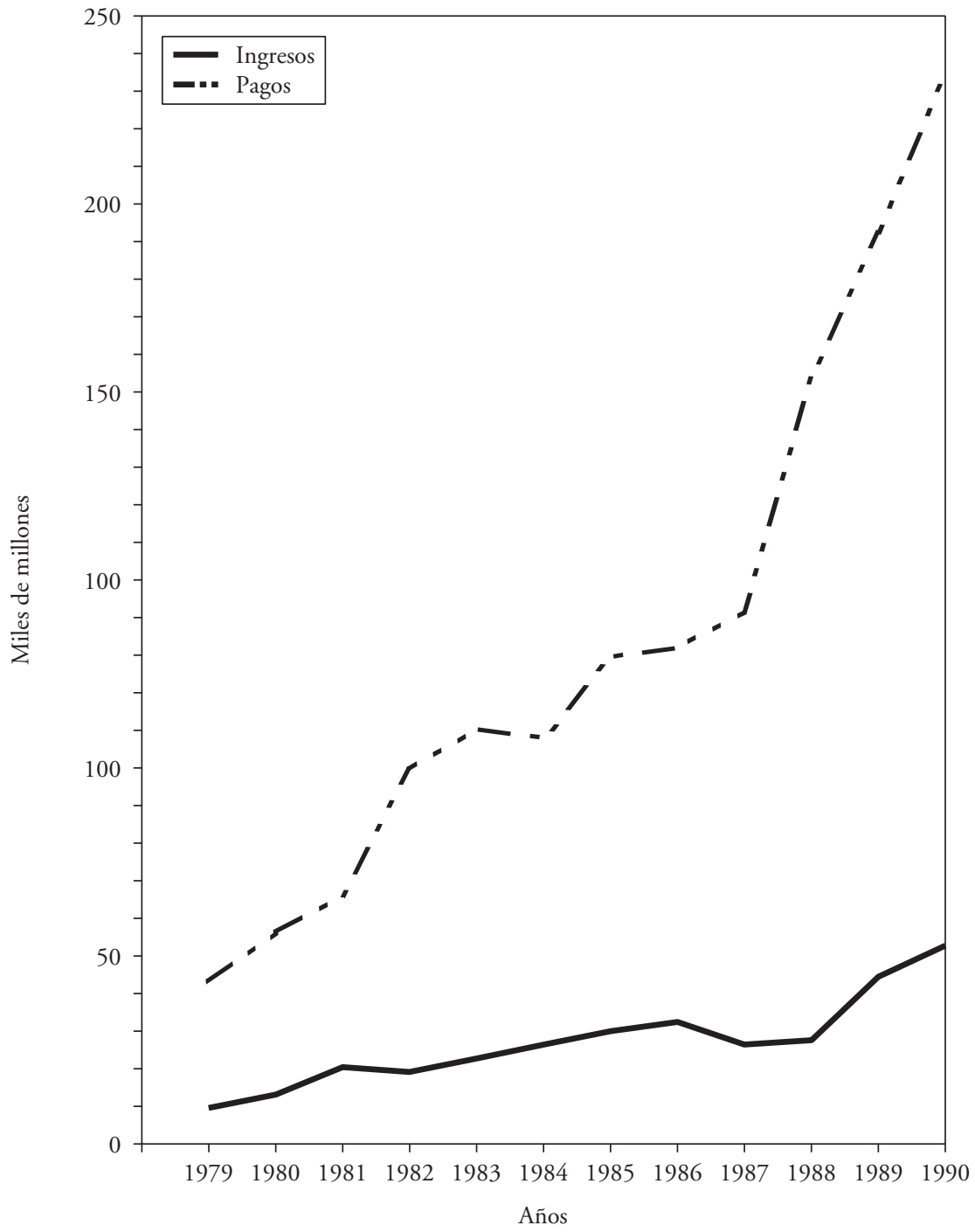

Para los años 1977, 1978 y 1979 se unen los conceptos: «Cánones-Marcas y Royalties» y «Asistencia técnica» bajo el epígrafe: "Asistencia Técnica y Royalties».

Fuente: Ministerio de Comercio. Balanza de Pagos de España. Madrid. Años 1972 a 1980. Véase también apartado: "Otros servicios diversos». Para derechos de autor.

Ministerio de Industria, Comercio y Turismo. Secretaría de Estado de Comercio, Balanza de Pagos de España 1980-1990, Madrid, junio 1991. 
En resumen:

- Se han incrementado muy significativamente las inversiones en $\mathrm{I}+\mathrm{D}$, aunque algo menos de lo previsto; el incremento se produjo sobre todo en la década de los años ochenta, produciéndose un estancamiento relativo en los primeros años de la década de los noventa.

- Nuestra distancia en inversiones respecto a los países adelantados de nuestro entorno se mantiene, estando España aún muy alejada de los mismos.

- Se ha producido también un aumento importante en el número de personal dedicado a la investigación y el desarrollo; en este aumento ha influido muy significativamente el incremento del profesorado universitario, que modifica los porcentajes relativos entre los distintos sectores y campos de investigación.

- La distribución de los gastos se ha modificado sin pautas claras que lo justifiquen.

- Se ha producido un mayor desplazamiento de la I+D hacia la investigación aplicada y el desarrollo, siendo más minoritaria la llamada investigación fundamental.

- La fuente básica de financiación es el Estado a través de sus distintos organismos nacionales, autonómicos y empresas públicas.

- La estructura del gasto difiere entre la que se da en los centros dependientes de la Administración y las empresas; los primeros han variado más, siendo los de las empresas más estables que los que había en la década de los setenta. De nuevo en esto parece haber influido el aumento del sector de los «Centros Superiores de Enseñanza».

- El déficit español en la balanza de pagos por transferencia tecnológica se ha incrementado espectacularmente, sobre todo a partir de los últimos años de la década de los ochenta. España, en ese sentido, es aún más dependiente tecnológicamente.

- Aunque continúa siendo muy minoritaria, se ha incrementado también significativamente la inversión en $\mathrm{I}+\mathrm{D}$ de las empresas extranjeras que operan en España. 


\begin{abstract}
Drawing on different sources of secondary data on Spain's $\mathrm{R}+\mathrm{D}$ expenditure, income and staff, this paper updates and extends the series used in previous years from 1974 and 1980 to 1992. On the basis of these tables, the author examines the main variations in research staff - different types of researchers and different fields and sectors of research - both in the public administration and in the private sector, also considering the sex of the research staff. He examines $\mathrm{R}+\mathrm{D}$ expenditure both from a general and a relative perspective, and draws comparisons with other European countries on the basis of sources of financing, the origin and use of research funds in the public and private sectors, and different fields and types of research. The paper ends with a nine-point summary of the main findings.
\end{abstract}

